\title{
تقاطعات القياس والاستقراء في مناهج العلوم الشرعية والتجريبية والإنسانية
}

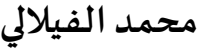 \\ باحث دكتوراه- كلية الآداب والعلوم الإنسانية- جامعة محمد الخامس- المغرب \\ mkbs114@gmail.com
}

تتكامل علوم الوحي والعلوم الكونية والإنسانية عند علماء المسلمين، ومن أوجه تكاملها: تقاطعها ( أي التقاؤها واشتراكها)

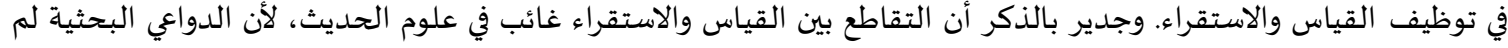

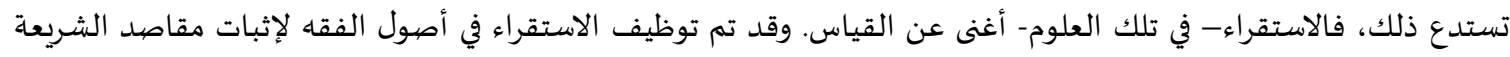

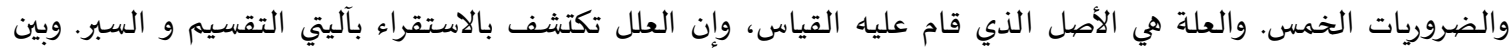

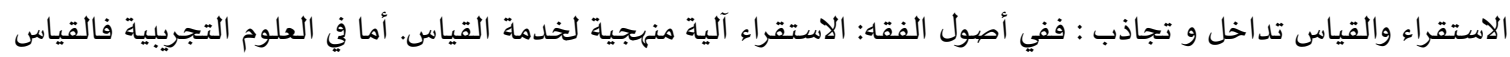

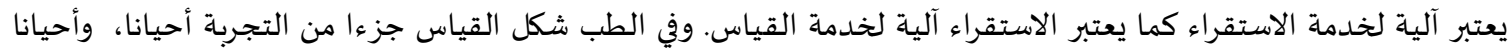

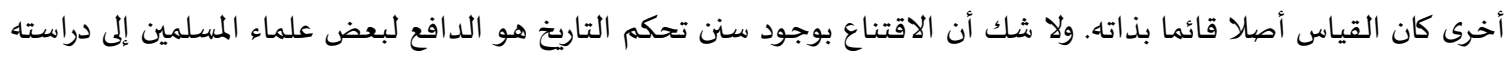
دراسة استقرائية، مثل ما قام بها ابن خلدون وابن الأزرق.

\section{(c) (7)}

الكلمات المفتاحية: القياس، الاستقراء، التقاطع، التكامل، العلوم التجرببية، العلوم الشرعية، العلوم الإنسانية.

أقصد بمصطلح" تقاطعات": ما تفيده المعاني الرياضية الهندسية، و خلاصة ذلك أن التقاطعات هنا هي: نقط التلاقي و

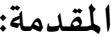

التشابك، فحين نقول: تقاطعت الطرق، فمعنى ذلك: تلاقت وتشابكت ؛ ولما نقول : تقاطع الخطان : قطع كل منهما الآخر (1). والمقصود بمصطلح "القياس" في هذه المقالة المفهوم المشترك بين القياس العقلي والقياس الفقهي الأصهولي : فالقياس العقلي-

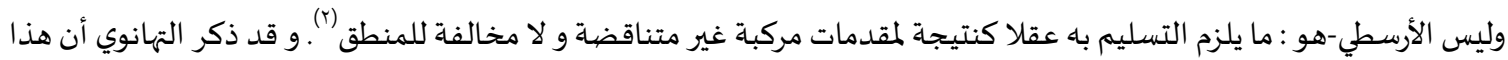



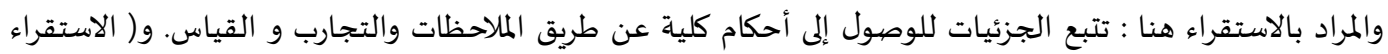

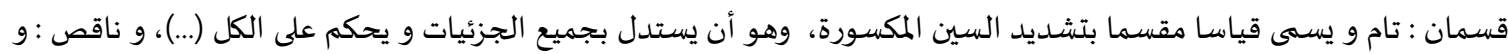

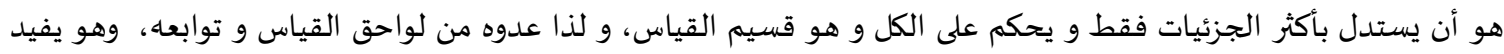

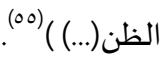

وحين يقال : في العلوم الشرعية والعلوم التجريبية والإنسانية عناصر مشتركة في طرقها ومناهجها ومنظومة مصطلحاتها،

فهذا يعني جوانب من التكامل المعرفي بين علوم الوحي والعلوم الكونية و الإنسانية. و تتناول هذه المقالة البحثية ثلاثة محاور في فقرات يسند بعضيها بعضيا:

الأول: تقاطعات القياس و الاستقراء في مناهج العلوم الشرعية (علم الحديث و علم أصول الفقها أنموذجين).

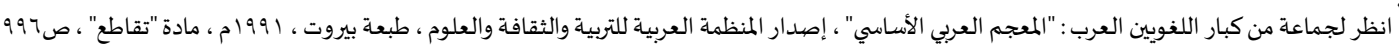

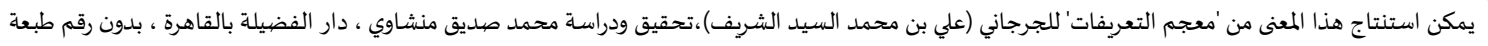

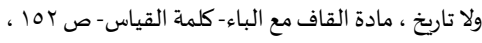

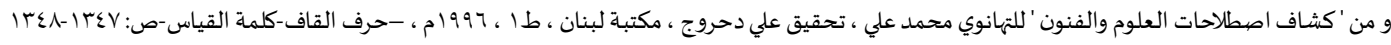

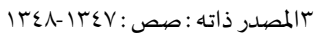

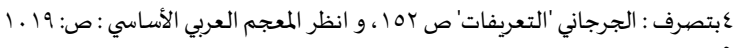

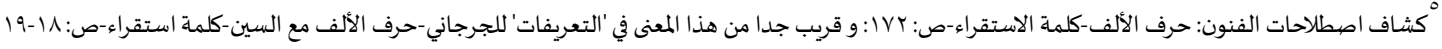


والثاني: تقاطعات القياس و الاستقراء في مناهج العلوم التجريبية عند المسلمين (علم الطب وعلم البصريات - الفيزياء- أنموذجين). والثالث: تقاطعات القياس و الاستقراء في مناهج العلوم الإنسانية (التاريخ أنموذجا)، من خلال إعمالهما من طرف كل من ابن خلدون وابن الأزرق

مشكلة البحث:

القياس والاستقراء آليتان ومنهجان من مناهج البحث في مختلف العلوم. ومن الأسئلة التي قد تخطر بذهن الباحث والقارئ: هل ثمة قواسم مشتركة وجسور متصلة وامتداد تكاملي بين العلوم الشرعية والتجريبية والإنسانية بحيث يكون القياس

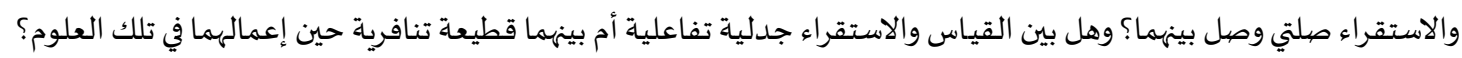

أهداف البحث:

يتبين من خلال إشكالية البحث أن أهم أهد افه تتجلى في :

بيان محل توظيف كل من الاستقراء في تلك العلوم.

إبراز أوجاه التداخل والتجاذب بين القياس والاستقراء.

تجلية العلاقة الرابطة بين التجربة والقياس والاستقراء.

كشف اللثام عن القواسم المشتركة (أي التقاطعات بالمعنى الرياضي) الواقعة بين القياس والاستقراء، وبين علوم الوحي

$$
\text { وعلوم الكون والإنسان. }
$$

أهمية البحث:

لعل أهداف البحث تتضمن إيحاءات إلى أهميته، حيث يكشف عن القواسم المشتركة بين القياس والاستقراء في مناهج

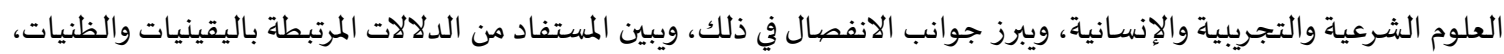
وعلاقة ذلك بمقاصد الشريعة الإسلامية، وبدوافع توظيف القياس والاستقراء في العلوم التجريبية والإنسانية.

الدراسـات السـابقة :

توجد دراسات كثيرة ومتنوعة حول مباحث القياس والاستقراء في مجال العلوم الشرعية، إما بشكل مستقل أو بشكل مضمن في كتب وأبحاث الفقه والأصيول، في حين أن الدراسات المرتبطة بالقياس والاستقراء في العلوم التجريبية والإنسانية أقرب إلى مرئ الندرة والقلة منها إلى الشيوع والكثرة.

وسأضرب صفحا عن ذكر كثير منها، وأكتفي بذكر ما أحسباء ذا أولوية وأهمية في اللمحة الإجمالية الآتية :

$$
\text { من الكتب المؤلفة : من }
$$

• كتاب " الاستقراء والمنهج العلمي "، للدكتور فهي زبدان، إصدار ونشر دار الجامعات المصرية بالإسكندرية، طبعة 19VV م.



واليقين، وعلاقة الاستقراء بالاحتمال.

كتاب "نظرية القياس الأصهولي: منهج تجريبي إسلامي" لمحمد سليمان داود، إصدار ونشر دار الدعوة بالقاهرة، طبعة

ع 19 ام/ع ـ ع اهـ ويتميز هذا الكتاب بالربط بين علم أصيول الفقه والعلوم التجريبية عند المسلمين.

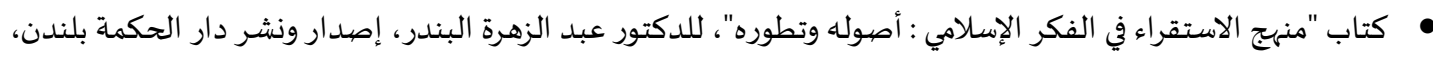

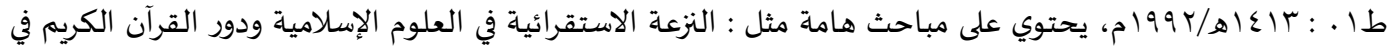
إرساء قواعد الاستدلال العلمي، ومنهج القياس الأصولي ومحتواه العلمي، والاستقراء والعلية، ومنهج القياس وحدود العلمية. • كتاب "منطق الاستقراء: المنطق الحديث" للدكتور إبراهيم مصطفى إبراهيم، إصدار ونشر دار المعارف بالإسكندرية، طبعة

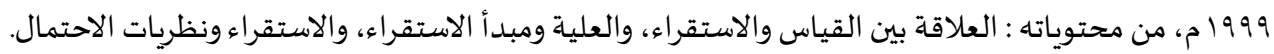
• كتاب "مناهج البحث في العلوم الإنسانية بين علماء الإسلام وفلاسفة الغرب"، للدكتور مصطفى حلمي، إصدار ونشر دار الكتب العلمية ببيروت، ط \ ـ :0 . . ب م. من محتوياته: الأقيسة العقلية البرهانية في القرآن الكريم. 
كتاب "منهج التعليل بالحكمة وأثره في التشريع الإسلامي : دراسة أصولية تحليلية" لرائد نصري جميل "أبو مؤنس"، إصدار


من محتوياته : التعليل بالحكمة أصل شرعي كلي قطعي، والتعليل بالحكمة والقياس الأصيولي... كتاب "الجامعون بين العلوم الشرعية والعلوم التجريبية" للدكتور عواد الخلف والدكتور قاسم علي سعد، سلسلة الثقافة

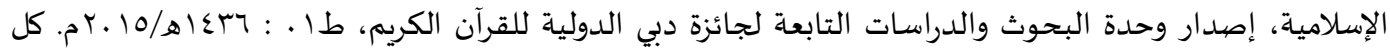

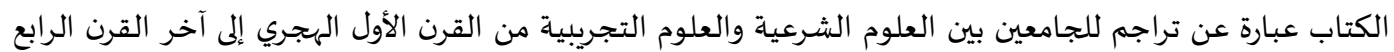

$$
\text { عشر للهجرة. }
$$

(ب) من الرسائل الجـامعية :

رسالة دكتور اه بعنوان "أثر القياس في بناء الفقه الإسلامي" لعبد الحليم عبد الفتاح السيد، بجامعاة الأزهر عام 9 الم. م. • رسالة ماجستير بعنوان "تعارض القياس مع الأدلة المتفق عليها عند الأئمة الأربعة والترجيح بينهما"، أعدها الباحث سعد

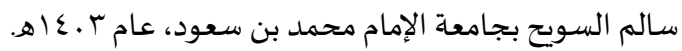
رسالة ماجستير بعنوان " نظرية القياس : دراسة منطقية أصولية مقارنة "، لمحمد طحطح بكلية الآداب بجامعة محمد

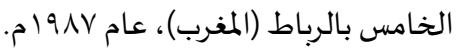
رسالة ماجستير بعنوان " القياس بين المنطق وأصول الفقه " لصالح نعمان، بجامعة الأمير عبد القادر بالجزائر، عام .01994 هرسالة دكتور اه بعنوان "تخصيص العلة ومخالقة القياس" لمحمد صالح الشيب، بالجامعة الأردنية، عام 991 م. رسالة ماجستير بعنوان " مناهج الأصهوليين في نقض العلة : دراساة أصولية تحليلية مقارنة" لمنصور محمود راجح مقدادي،

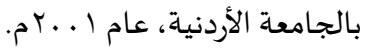
• رسالة ماجستير بعنوان "القياس في القرآن والسنة النبوية : دراسـة نظرية تطبيقية" ،لوليد بن علي الحسين، بجامعة الإمام

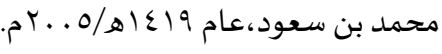
رسالة دكتور اه بعنوان " أثر تحقيق المناط في الفتوى" لمحمد شاهر محمد سعيد، بالجامعة الأردنية، عام 9 ـ . ب م.

• بحث " منهجية البحث العلمي عند علماء المسلمين" للدكتور محمود أحمد "أبو سمرة" والدكتور عماد أحمد البرغوثي،

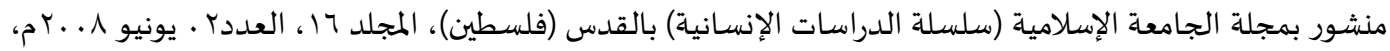

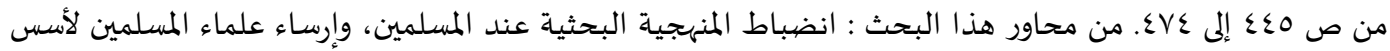
المنهجية الحديثة. بحث "جهود علماء المسلمين في إرساء المنهج العلمي"، لمحجوب محمد الحسيني، منشور بمجلة دراسات تربوية التي تصهدر

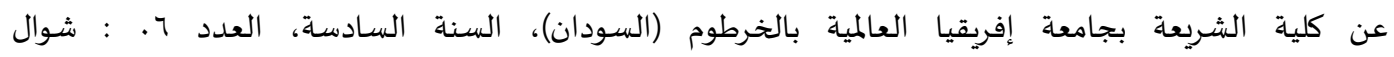

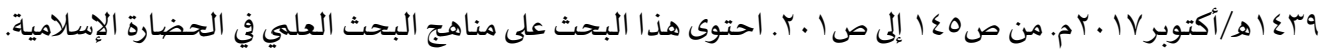
من المؤتمرات :

• بحث " العلوم الشرعية وأثرها في دراسـة العلوم الكونية والإنسانية" لعبد الرحمان بلعالم، منشور ضمن مباحث المؤتمر الوطني الأول حول دور العلوم الإسلامية في إرساء الهوية ومواجهة التحديات المعاصرة، والمنعقد بالأغواط بالجزائرة دائر، مايو

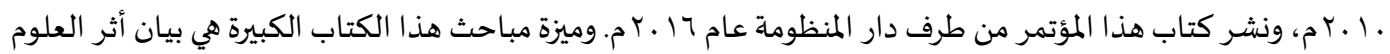
الشرعية في دراسة علوم اللسان والعلوم الكونية والإنسانية.

خطة البحثث : (1) - (1) المنهج الموظف في هذا البحث هو المنهج التحليلي الذي يقتضي الشرح والتفسير والتعليل، وتمت صياغته (بعد تحديد المشكلة والأهداف والأهمية ولمحة عن الدراسات السابقة) وفق الهيكلة الآتية :

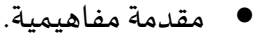
• المحور الأول : تقاطعات القياس والاستقراء في مناهج العلوم الشرعية (علم الحديث وعلم أصول الفقه أنموذجين). 
• المحور الثاني : تقاطعات القياس والاستقراء في مناهج العلوم التجربيية عند المسلمين (علم الطب وعلم البصريات



• المحور الثالث : تقاطعات القياس والاستقراء في مناهج العلوم الإنسانية (التاريخ أنموذجاً).

خاتمة ملخصية لنتائج البحث.

المحور الأول: تقاطعات القياس و الاستقراء في مناهج العلوم الشرعية ( علم الحديث و علم أصهول الفقه

(أنموذجين)

لعل الد ارس لعلم الحديث و علم أصهول الفقه يدرك تمايز هذين العلمين في توظيف آلية القياس وتقاطعهما في إعمال آلية

الاستقراء : ففي علم الحديث يكتفي علماؤه بإعمال الاستقراء دون القياس، بينما في علم أصول الفقه يزاوج علماؤه بين استعمال

هاتين الآليتين :

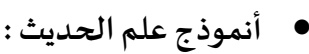

أسس علماء الحديث مناهج للقبول و الرد رواية و دراية من خلال مباحث الجرح والتعديل ومصطلح الحديث و علم

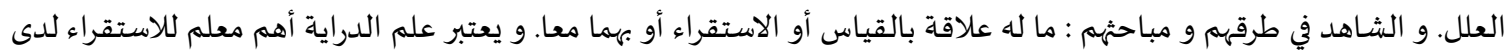

علماء الحديث.

إن علم الدراية في علم الحديث هو "فهم و تتبع و بحث و معرفة بالتراجم و الطبقات و أحوال الرواة، و خبرة بالمتون و

الألفاظو أنواع الترجيح، و إدراك عميق للعلل الخفية، و رؤية واسعة للحركة الحديثية عبر العصور و على اختلاف الأقطار"(جآ.

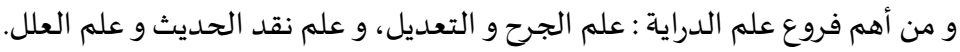

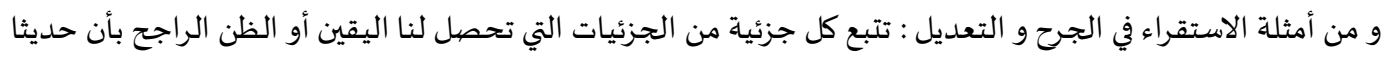

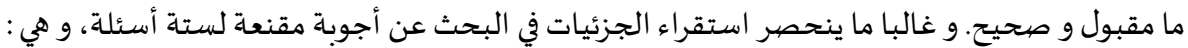

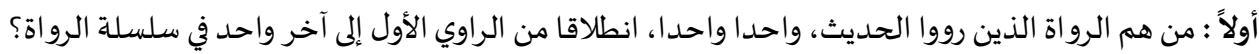

ثانياً : هل الراوي عدل في دينه و أمانته؟

ثالثاً : هل الراوي متقن لخبره؟

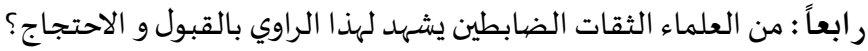

خامساً : كيف نطمئن إلى سلامة الخبر من خطأ الرواة و أوهامهه؟

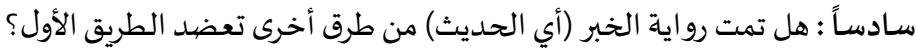

فلو أخذنا حديثا نطبق عليه استقراء أجوبة مقنعة لهذه الأسئلة الستاة فإننا سنحكم بقطعية ثبوتا إن كان متواتراو و

بصحته إن كان من خبر الآحاد. و كيفما كان الأمر فإن أقل ما نبتغي تحصيله من الاستقراء هو الظن الراجح فئه إنهاء إثبات الصحهة. وقد ضرب الدكتور همام عبد الرحيم سعيد مثالا من الأحاديث التي ثبتت صحتها انطلاقا من الأجوبة المقنعة للأسئلة السابقة،

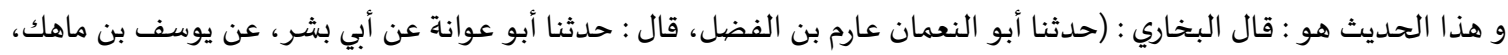

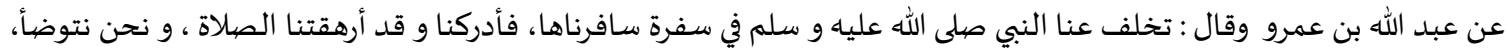

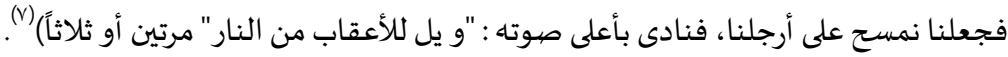

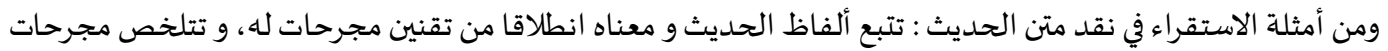

المتن في العناصر الآتية() :

ا. مناقضية معنى الحديث لحكم إسلامي مقرر أو نص شرعي مقطوع باه دون أن يقبل متن الحديث تأويلا يلائم معناه ذلك الحكم

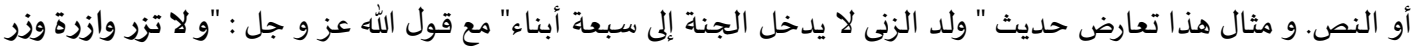

أخرى"

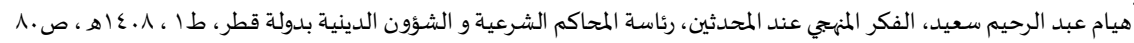

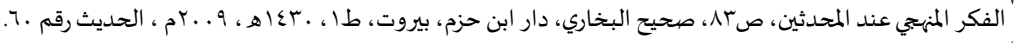

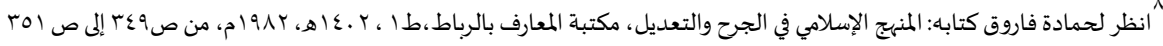


r. معارضة متن الحديث لمستلزمات العقول السليمة و قوانين الطبيعة مثل هذا الحديث الموضوع : (...قيل : يا رسول الله من ربنا؟ قال : لا من السماء، و لا من الأرض، خلق خيلا، فأجراها فعرقت فخلق نفسـه من ذلك العرق...)، فالحديث باطل عقلا

ومنطقا. r. مخالفة متن الحديث للحقيقة التاريخية أو الواقع و الوضع الاجتماعي المقرر بإجماع المسلمين : مثال ذلك : ما نسب إلى أنس

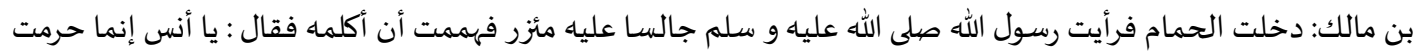


و سلم معروفة.

فإذا خالف متن الحديث الحقيقة التاريخية أو الإجماع فإن ذلك دليل على أن الحديث لا أصل له أو أنه منسوخ. والخلاصية أن تتبع ألفاظ المتن من خلال مجرحاته مظهر من مظاهر الاستقراء في علم الحديث. ومن أمثلة الاستقراء في علم علل الحديث : تتبع و تعقب روايات الثقات لأن أمرهم قد يخفى بسبب الثقة المبن الموضيوعة فيهم،

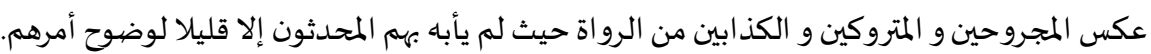
وقد عرف المحدثون الحديث المعلل بأنه "خبر ظاهره السلامة لجمعاه شروط الصحاة، لكن فياه علة خفية قادحة، فيها

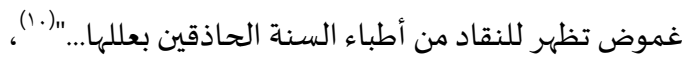
لما يتم الفحص عنها بعد جمع طرقه. فالحديث المعلل توفرت فياه شروط الصحنة الصداء، فهو سليم من الناحية الظاهرية، لكن إعمال نقد المتن في معناه يكشف عن علة خفياة تدرك بفراسـة حذاق

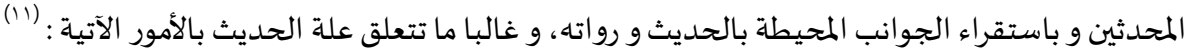
أن يكون الراوي ضابطا متقنا لأحاديث شيوخه ما عدا واحد منهم لم يتمكن من إتقان أحاديثه، فيقع أن يروي حديثا لم يتقنه من مرويات شيخه المذكور، فيخفى ذلك على العلماء و لا يعرفه إلا خبراؤهم المتمرسون. أن يحدث بالحديث في بلد غير بلده فيخطئ فياه بسبب مفارقته لكتبه و بعده عنها. أن يحدث بسند ليس هو سند الحديث و هو يظن أنه سنده. أن يكون قد سمع من شيخهاء دون أن ينتبه إلى عيب في نطقه و لسانه فيقع في تغيير الحرف أو تحريف الكلمة. أن يروي الحديث بمعناه فيختصره فيبدل حقائقه و هو لا يشعر. أن يحدث بالحديث في شيخوخته و بداية هرمه فيخلط الحقيقة بالخيال بسبب ما يطرأ على الذاكرة من ضعف كبر السبر السن.

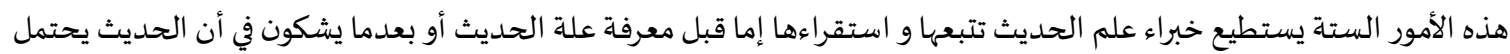
أن يكون معلولا.

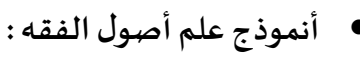

أكد أبو إسحاق الشاطبي (ت . ع هـ) أن أصول الفقه قطعية بالاستقراء : قال في المقدمة الأولى من كتابه "الموافقات" :

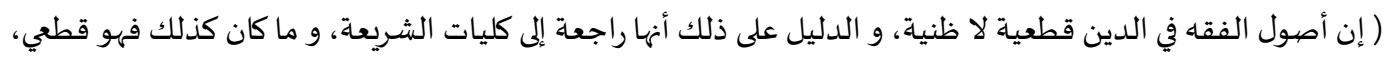

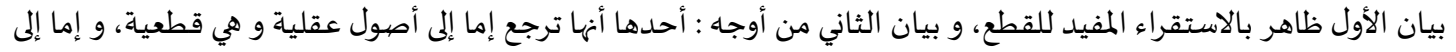

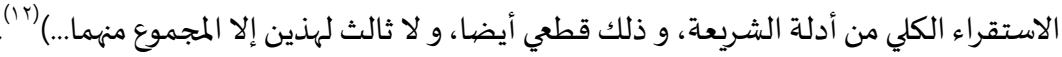
وبالتأمل في هذا النص، نلاحظ أن المصطلحات الأصولية الموظفة فياه مصطلحات تستعمل في المنهج الاستقرائي، و هي: أصول:-قطعية- ظنية- دليل- كليات- استقراء- أصول عقلية. إن لكل مصطلح من هذه المصطلحات دلاتلهات فلها في علم أصول الفقه و غيره من العلوم الشرعية و التجريبية و الإنسـانية. ومعلوم أن الشاطبي أصل لمباحثه في 'الموافقات' موظفا المنهج الاستقرائي في ذلك، حيث أعلن عن هذا المبنه المنهج منذ بداية

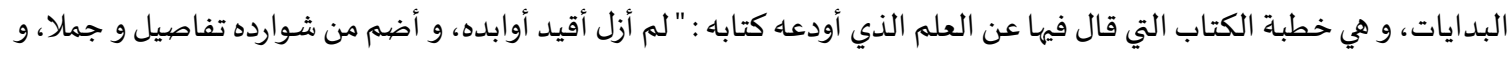

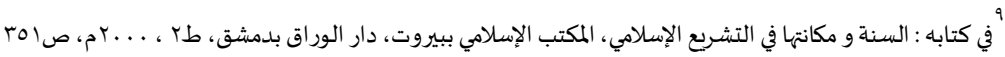

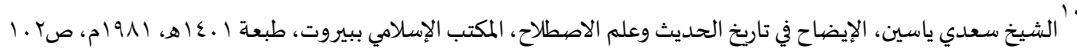

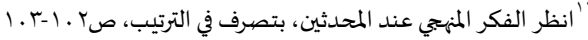

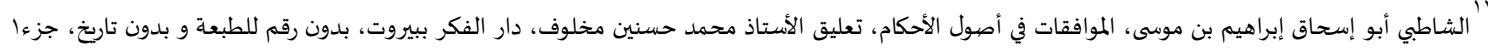


أسوق من شواهده في مصادر الحكم و موارده مبينا لا مجملا، معتمدا على الاستقراءات الكلية، غير مقتصر على الأفراد الجزئية، و

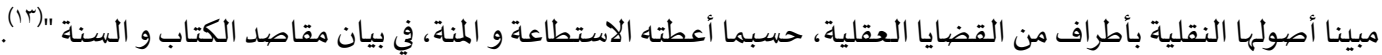
يبرز هذا النص أن الشاطبي جمع العلم وضهم بعض فروعه إلى بعض مفصهلا ومجملا، و أخذ استشهاداته و بينها من مصادر الحكم. واعتمد منهج الاستقراء الكلي لا الجزئي، رادا كل المفردات المستقرأة إلى مظانها من القرآن و السنة، معملا فيها الاجتهاد العقلي حسب ما أوصلته إليه طاقته، وذلك كله غرضاه بيان المقاصيد الشرعية.

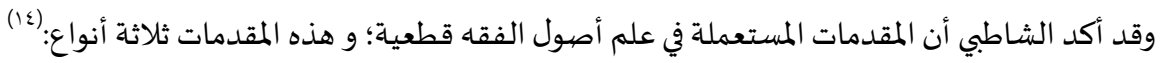
مقدمات عقلية، كأن ترجع إلى أحكام العقل الثلاثة : الوجوب والجواز والاستحالة. و مقدمات عادية: و مسلكهاو تصرفها مثل العقلية. و مقدمات سمعية : و أهمها ثلاثة أقسام :

المستفادة من الأخبار المتواترة لفظا القطعية دلالة.

و المستفادة من الأخبار المتواترة معنى.

و المستفادة من موارد الشريعة بالاستقراء.

و تجدر الإشارة إلى أنه بين أن استعمال الأدلة العقلية في علم أصول الفقه يكون مبنيا على الأدلة السمعية و أن توظيفها

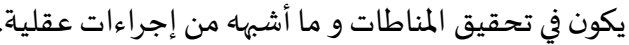
كما أبرز أن آحاد الأدلة الشرعية ظنية لا تفيد القطع إلا بتضافرها على معنى واحد، و لا يعرف ذلك إلا بمنهج الاستقراء

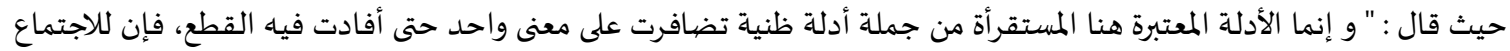
من القوة ما ليس

للافتراق "(1010) مو بين أن مقاصدد الشريعة و الضروريات الخمس مثبتة بالاستقراء، أي باستقراء آحاد الأدلة الشرعية(17).

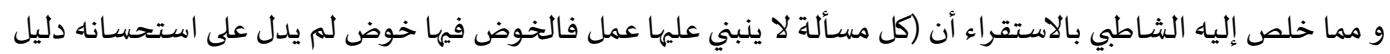
شرعي) مبرزا أنه يعني (بالعمل عمل القلب و عمل الجوارح من حيث هو مطلوب شرعا)، و استدل على ذلك الاستنباط بقوله : (و

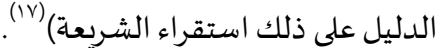

ومن خلال دراساته الاستقرائية، حصر أوصاف العلم القطعي في ثلاث خاصيات :الاطراد، والثبوت، والحاكمية(1) :

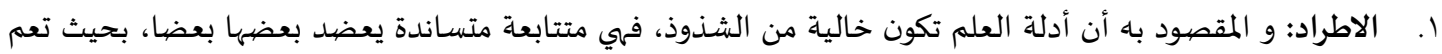
مواضع الحكم و تنتظم فياه.

r. الثبوت: و المقصود باه أن علوم الشريعة و كلياتها ليست زائلة و لا متغيرة، و لذلك لا يلحقها نسخ بعد كمالها و لا تخصيص لعمومها و لا تقييد لإطلاقها و لا رفع لحكم من أحكامها. r. الحاكمية: أي هذا العلم (علم الشريعة) يكون حاكما لا محكوما عليه، فهو يفيد العمل ويأمر باه ويدعو إليه، و ليس في العمل ما هو حاكم على الشربعة، بل هي الحاكمة عليه.

و خلاصة هذا أن العلم الذي تثبت له خواص العموم و الاطراد و الثبوت و الحاكمية هو الذي يعتبر من صلب العلم.

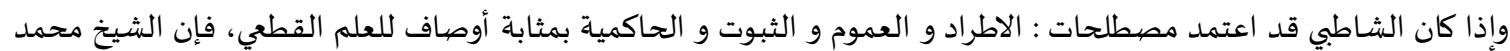

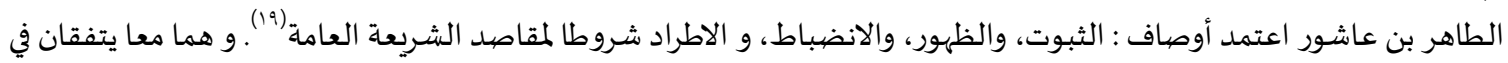

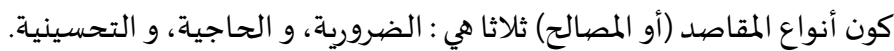
واعتبر الأصوليون العلل معايير للكشف عن المقاصد. و يراد بالعلة عندهم" معنى في المحكوم علياه يدرك العقل مناسبته لبناء حكماه الشرعي عليه"(r.)

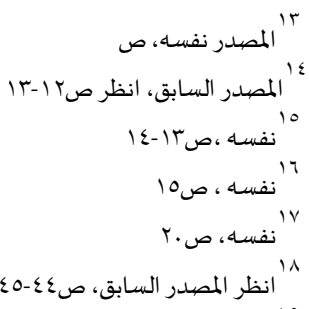

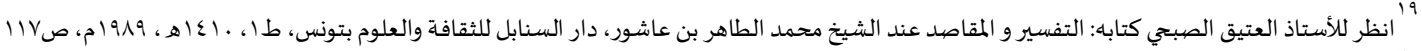

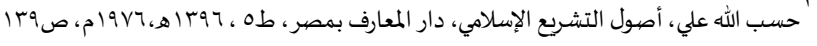


و هي: (الوصف الظاهر المنضبط المناسب للحكم كالإسكار بالنسبة للخمر)('). و بهذا الاعتبار أضحت العلة الأصل الذي قام عليه القياس، إذ القياس أساس تعليل النصوص، و التعليل عند جمهور الأصهوليين يكون بالوصف الظاهر المنضبط المناسب (rr).

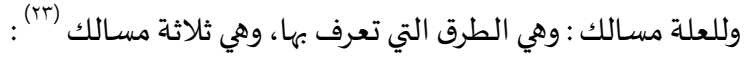

• المسلك الأول: النص الشرعي من القرآن أو السنة سواء كان صريحا في الدلالة على العلة أو كان مومئا إليها.

• • المسلك الثاني: الإجماع.

• المسلك الثالث: المناسبة : أي البحث في الأصل المنصوص على حكماه عن وصف مناسب عقلا لبناء الحكم عليه.

وهذه المسالك موارد للاستقراء، حيث إن علل الأحكام- عند الأصوليين- تستخرج و تشتق من النصوص أو من الإجماع أو

من الاستنباط عن طريق إعمال منهج المناسبة، و ذلك ثابت بالاستقراء (rع).



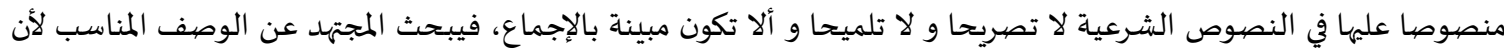

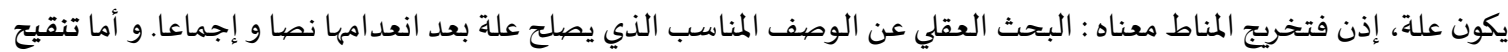
المناط : فهو التعرف عن الوصف الذي يصلح علة من بين عدة أوصاف وذلك باستبعاد كل وصف غير مناسب حتى يتعرف على المناسب وينتهي إليه. وأما تحقيق المناط : فهو أن تكون العلة قد عرفت بشتى الطرق المرق فينظر المجتهد في الفروع لمعرفة تحقق مناط

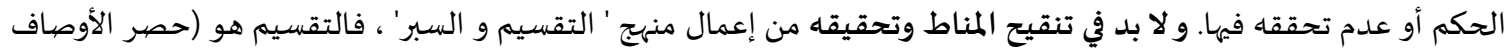

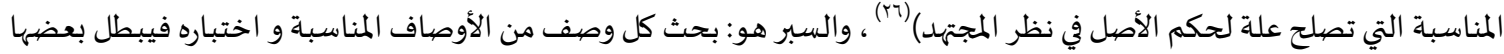
و لو بدليل ظني و يبقي على الوصف غير المحتمل للإبطال فيجعله علة (rV). وحري بنا التنبيا إلى أن منهج (التقسيم و السبر) معلم هام من معالم المنهج الاستقرائي الذي كان له الأثر الكبير في المنهج

التجريبي لدى العلماء المسلمين الذين اشتغلوا بالطب والكيمياءو الفلك والفيزياءو غير ذلك من العلوم.

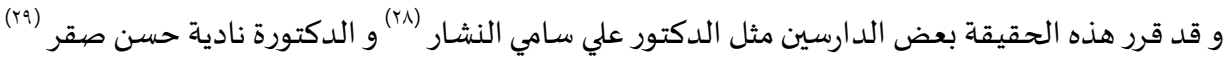

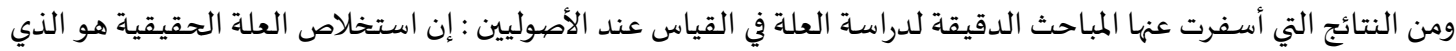
يمكن من تعميم أحكام الاستقراء، أما قبل استخلاصها فلا يمكن ذلك. وقد سبق الأصيوليون إلى تقرير هذه الحقيقة المتعلقة بالاستقراء. (r.)

\section{المحور الثاني : تقاطعات القياس والاستقراء في مناهجج العلوم التجريبية عند المسلمين أنموذج علم الطب: 1. 1 القياس:}

ارتبط القياس بالتجربة عند علماء الطب المسلمين، و قد جعل الرازي معرفة القياس وسيلة لامتحان الطبيب، قال: ( و أما

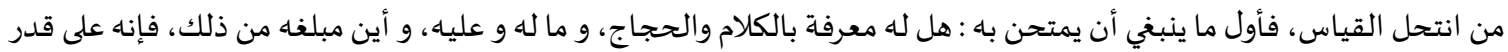

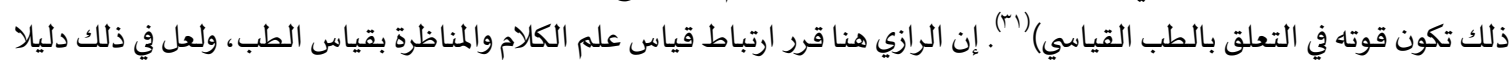
على تأثر الأطباء المسلمين بالعلوم الشرعية كعلم الكلام وعلم أصول الفقه، حيث اعتبر الرازي نجاح الطبيب في قياس علم الكلام دليلا على درايته بالقياس الطبي.

$$
\begin{aligned}
& \text { "أبو زهرة محمد، أصول الفقه، دار الفكر العربي، بدون رقم للطبعة و بدون تاريخ، صYrV } \\
& \text { آن المرجع و الصفحة نفسهما. }
\end{aligned}
$$

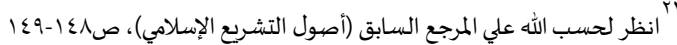

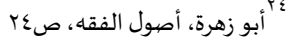

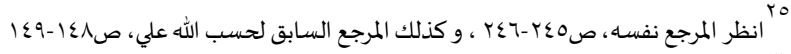

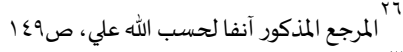

$$
\begin{aligned}
& \text { "انظر المرجع و الصفحة نفسيهما }
\end{aligned}
$$

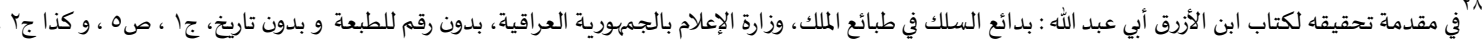




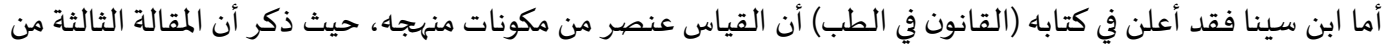

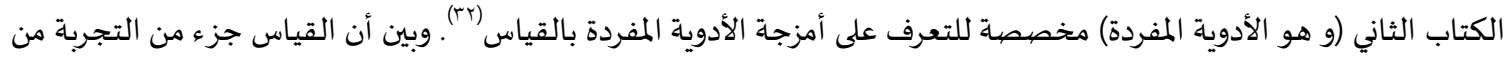

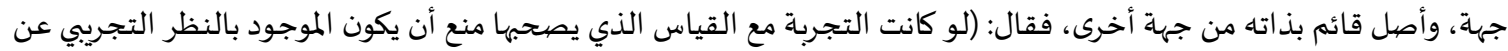

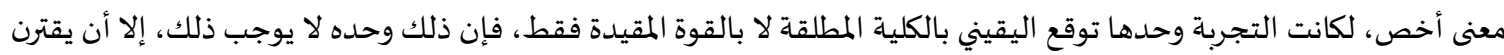

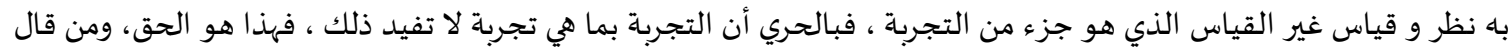

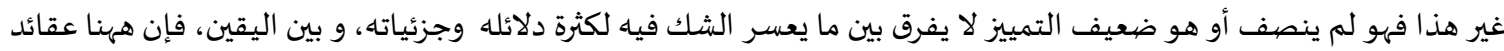
تشبه اليقين و ليست باليقين).

و خلاصة هذا النص تقرير القضايا الآتية: أولاً: التجربة وحدها لا تفيد اليقين.

ثانياً: التجربة المصاحبة للنظر و القياس الأصلي الكلي تكسب اليقين التين و توقعه. ثالثاً: الظان بأن التجربة وحدها تفيد اليقين مخطئ بسبب عدم إنصافه التهاه أو تمييزه الضعيف.

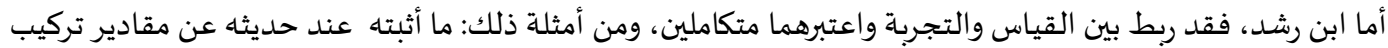

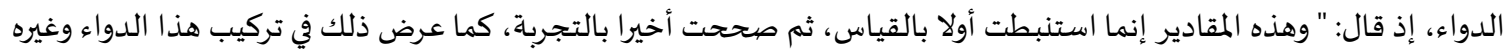

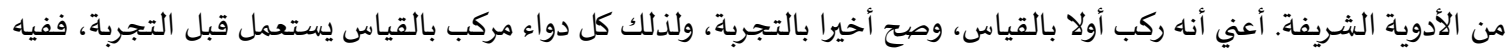



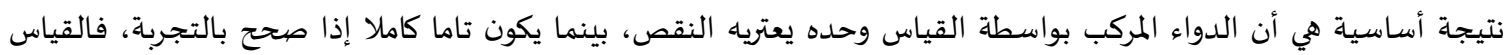
والتجربة -إذن- متكاملان متلازمان. أما داوود الأنطاكي فقد أبرز أن طرق و أصيول استفادة المنافع من الأشياء في العمل الطبي ثلاثة: الوحي والتجربة والقيان القياس

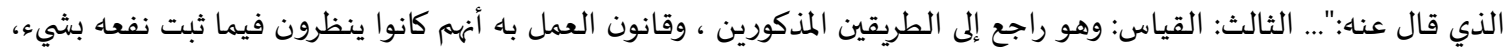

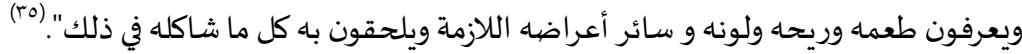

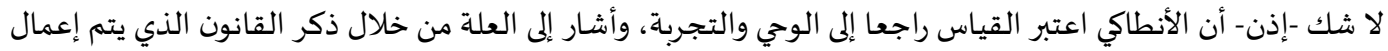

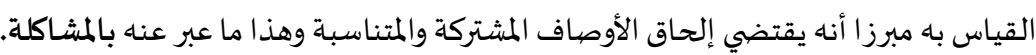

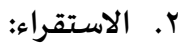

صرح الرازي بممارسته للاستقراء، حيث قال في مقدمة كتابه: (منافع الأغذية ودفع مضارها): "وإني لما أجلت الفكر في أن النا

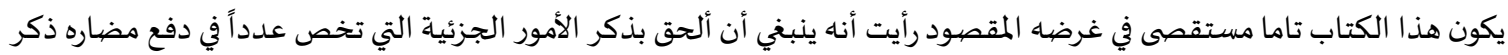

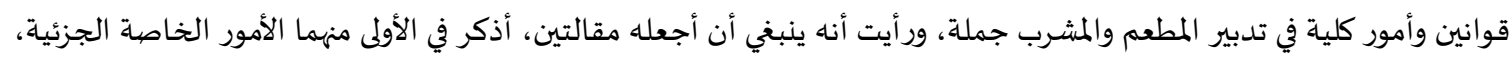

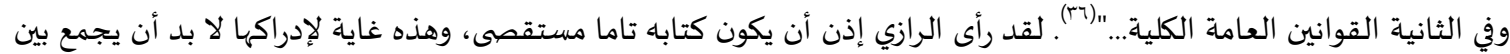

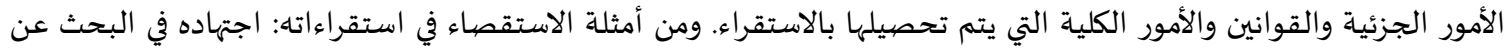

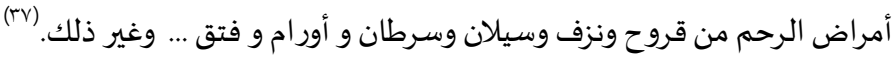

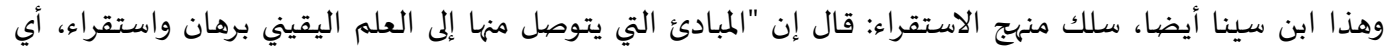

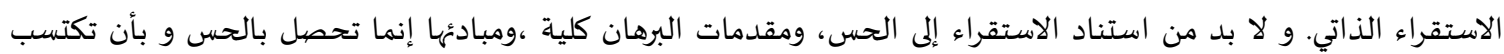

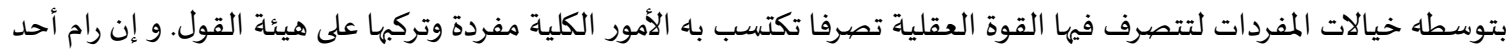

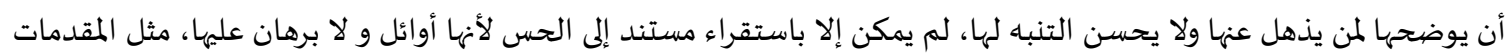

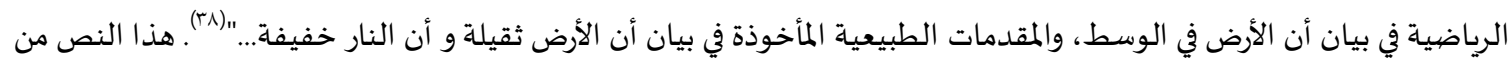

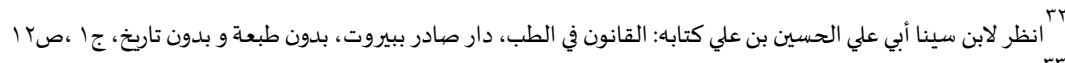

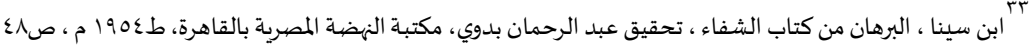

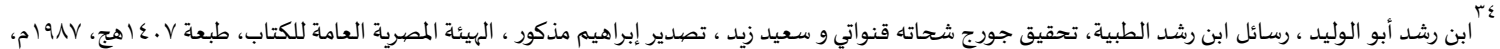

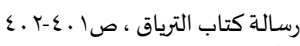

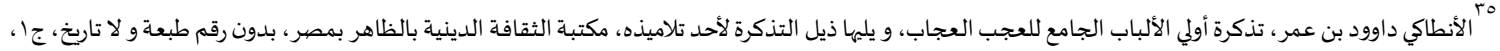

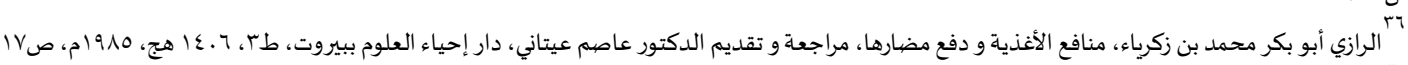

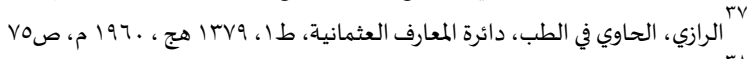




كلام ابن سينا يقرر أن العلم اليقيني يكتسب عن طريق البرهان، والاستقراء الحسي، و ذلك بإعمال العقل في المقدمات التي تكون

ووظف ابن سينا التقسيم والسبر في استقرائه: و هذا مثال على ذلك: قال:" الأجسام من جهة قواها لا تعقل إلا على أحد إحد

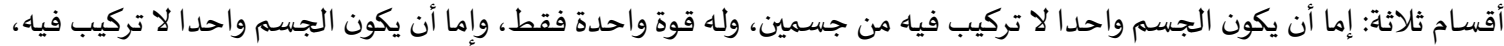

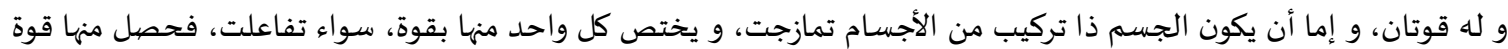

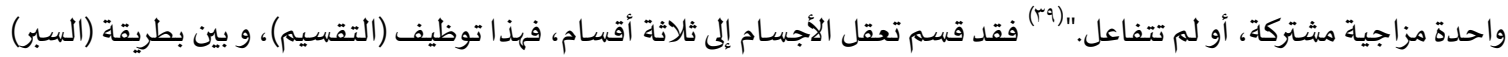

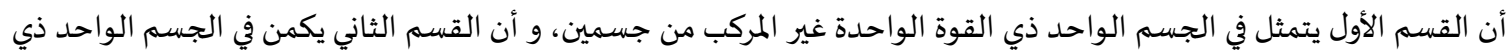

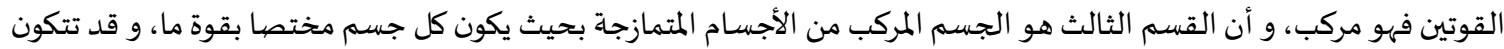



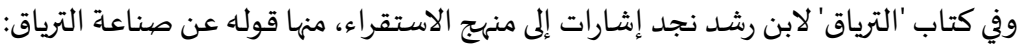

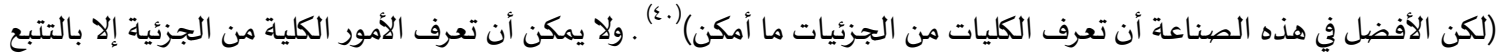

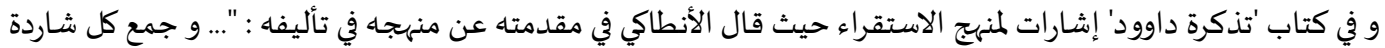

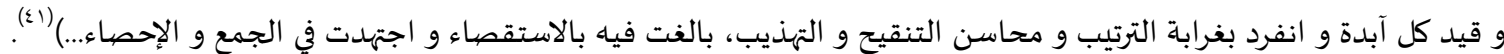
فالجمع والتقييد و الترتيب و التنقيح و التهذيب و الإحصاءو الاستقصاء، كلها ألفاظ تدل على الاستقراء.

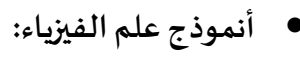
يعتبر ابن الهيثم رائد علم الفيزياء عند المسلمين في أبحاث الضوء والبصريات، تلك الأبحاث التي أعمل فهيا المنهج



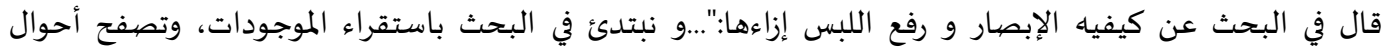

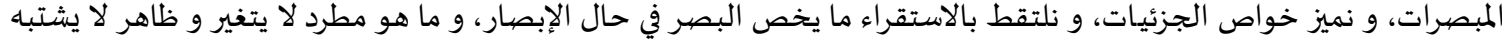

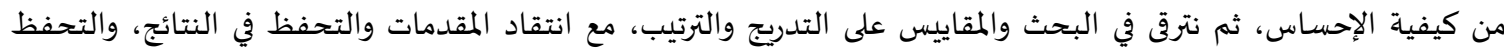

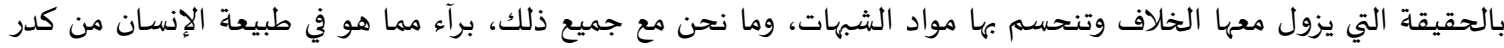

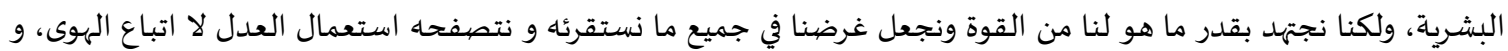

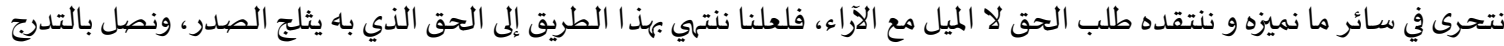

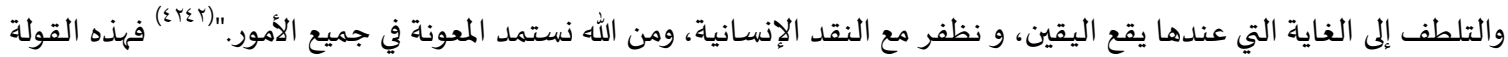

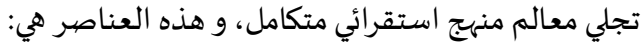
أولاً: استقراء الموجودات ثانياً: تصفح أحوال المبصرات المودات ثالثاً: تمييز خواص الجزئيات الموات المئرات رابعاً: البحث في الاطراد و الخصوصية من خلال الاستقراء

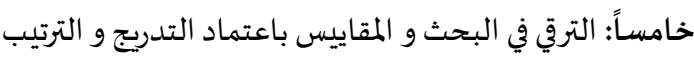

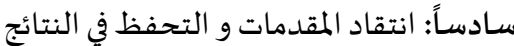
سابعاً: العدل و النزاهة في البحث، و ترك الذاتية و الهوى: أي سلوك الموضوعية: و هذا هو الغرض في جميع المستقرآت. ثامناً: تحري طلب الحق في سائر المميزات والمنتقدات. وفي آخر القولة قرر ابن الهيثم أن الهدف العام هو الوصول إلى اليقين و الحقيقة. وقد كان متواضعا منصفا حينما اعترف بنقصيان الإنسان، فهو لذلك يستمد العون من الله في كل الشؤون.

'ابن سينا، الشفاء (الطبيعيات) ، مراجعة و تقديم الدكتور إبراهيم مذكور ، تحقيق الدكتور محمود قاسم، دار الكتاب العربي بالقاهرة، سلسلة المكتبة العربية ، إصدار وزارة

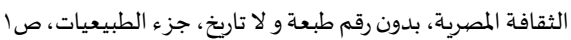

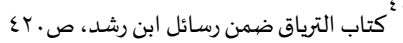

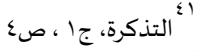




وقد طبق هذه العناصر في بحثثه لقضايا الإبصار. و هذه خلاصية لما قاله عن خواص البصر (r)؛:

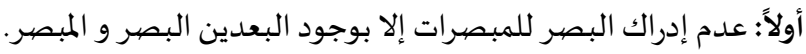

ثانياً: عدم إدراك البصر للمبصر إدرال إلا بالتقابل بينهما مع وجود خطوط مستقيمة متوهمة بينهما دون وجود جسم كثيف يتوسط بينهما

يقطع جميع الخطوط المستقيمة. ثالثاً: كل مبصر يدركه البصر بشرط انتفاء الجسم الكثيف بينهما و أن يكونا معا في هواء واحد متصل و أن يكون الإدراك بغير

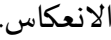
رابعاً: لا يستتر من الشيء المبصر إلا الجزء الذي تقطع الخطوط المستقيمة بينه و بين البصر بجسم كثيف.

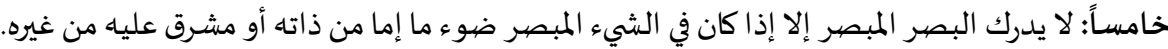

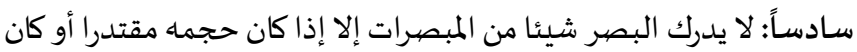

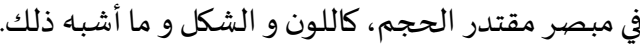

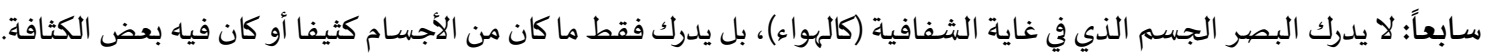

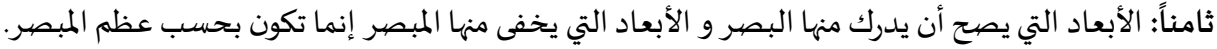
تاسعاً: الأبعاد التي منها يصح أن يدرك البصر المبصرات و الأبعاد التي تخفى منها المبصرات إنما تكون بحسب الأضواء التي في المبصرات. عاشراً: الأبعاد التي يصيح أن يدرك منها البصر المبصرات و الأبعاد التي تخفى منها المبصرات إنما تكون بحسب ألوان المبصرات. حادي عشر: لقوة البصر أو ضعفه تأثير في إدراك المبصرات أنسات أو عدمانها. ثاني عشر: أبعاد إدراك البصر للمبصر متعددة:و هي إما أبعاد معتدلة (و هي التي يظهر منها المبصر)، و إما أبعاد خارجة عن الاعتدال (و هي التي يخفى منها المبصر). هذه العناصر الاثنا عشر هي خلاصة خواص البصر التي توصل إلى استخلاصها ابن الهيثم عن طريق الاستقراء. و هي في مجموعها تنم

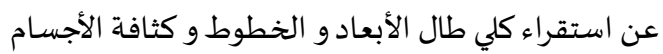
و أضواءها الذاتية أو المشرقة عليها، و الشفافية و الألوان، و القوة و الضعف في حاسة البصر.

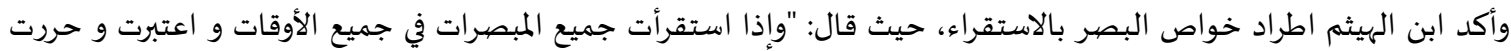

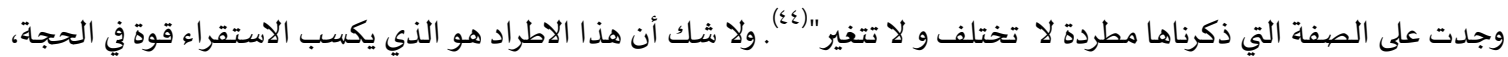
بل و قطعية في الحكم.

\section{المحور الثالث: تقاطعات القياس و الاستقراء في مناهج العلوم الإنسانية (التاريخ أنموذجاً)} ثمة تحفظ لدى بعض الدارسين في إطلاق صفة 'العلمياة' على المعارف الإنسانية، مثل الدراسات التاريخية و الاجتماعية و

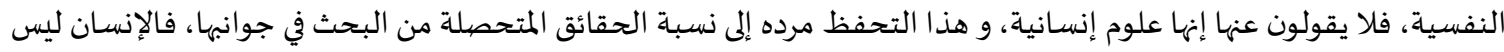

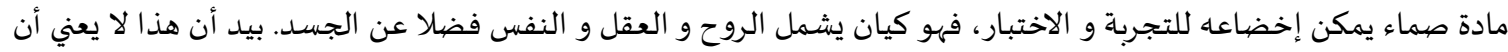

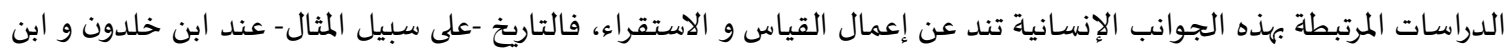

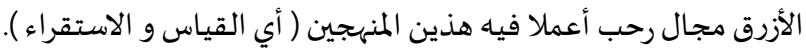
وكان القرآن الكريم دافعا قويا لعلماء التاريخ المسلمين نحو ذلك، فكتاب الله عز و جل دعا إلى استقراء الحوادث التاريخية لاستخلاص العبر منها، مثل قوله تعالى:" أفلم يسيروا في الأرض فينظروا كيف كان عاقبة الذين من قبلهم دمر الله عليهم، و للكافرين

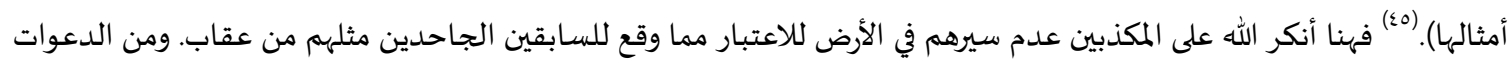

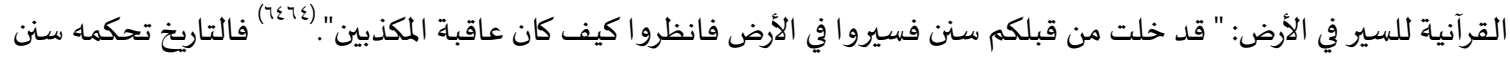

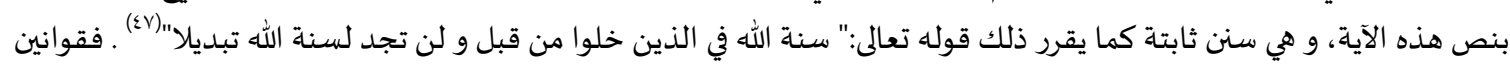

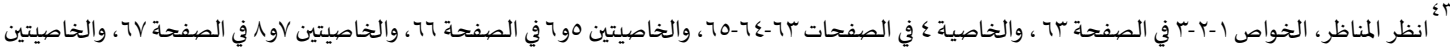

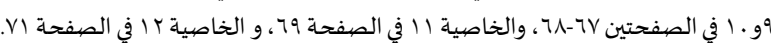

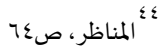
1)

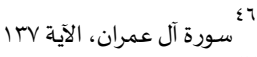

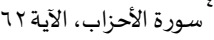


التاريخ غير متبدلة و لا متغيرة، و هذا ينسجم مع ما اقتضته الإرادة الإلاهية من ثبات في السنن. (إن التاريخ البشري لا يتحرك فوضى آنه

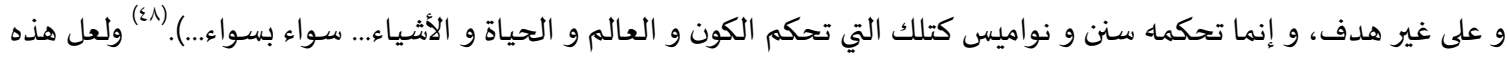
السننية التاريخية هي التي دفعت بعض علماء علدهاء المسلمين إلى دراسة التارتخ دراسة استقرائية كما فعل ابن خلدون و ابن الأزرق: إعمال ابن خلدون للقياس والاستقراء: انتقد ابن خلدون منهج كثير من المؤرخين قائلا:" ... فقد زلت أقدام كثير من الأثبات والمؤرخين الحفاظ فئس في مثل هذه

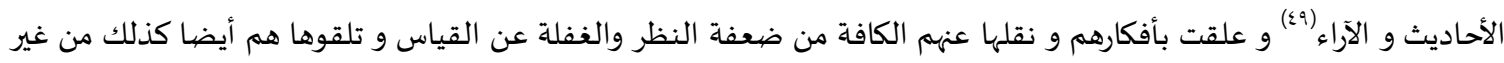

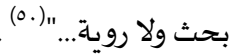
فقد عاب على أولئك المؤرخين عدة مزالق منهجية منها الغفلة عن القياس.و في هذا دليل على أن القياس معلم من معالم


الفرق، قال:".. يحتاج صاحب هذا الفن إلى العلم بقواعد السياسة و طبائع الموجودات و اختلاف الأمم و البقاع والأعصار(...) و

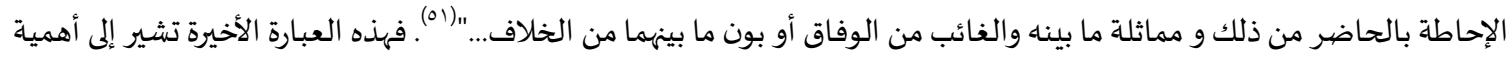

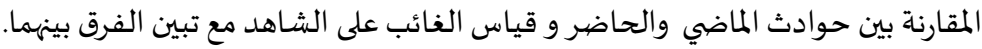

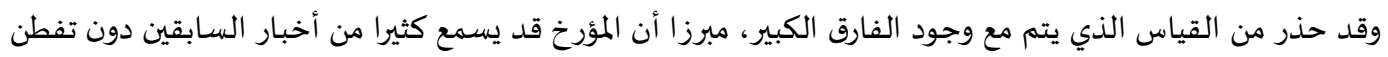

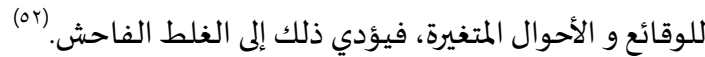

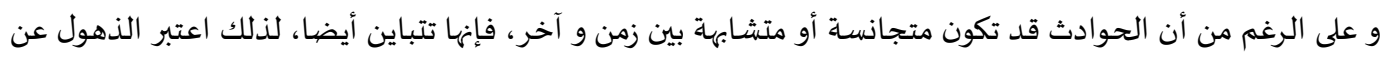

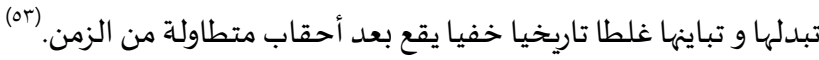

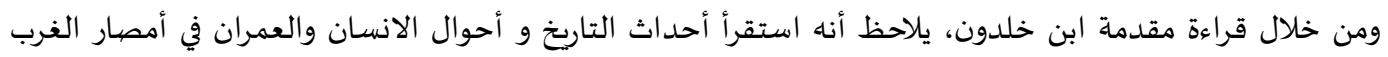
الإسلامي، فاستطاع عبر استقراءاته تلك استخلاص قواعد من مثل: أهل البدو أقرب إلى الخير من أهل الحضر. نهاية الحسب في العقب الواحد أربعة آباء. • • العرب لا يتغلبون إلاعلى البسائط. • لا يحصل الملك للعرب إلا بصبغة دينية من نبوة أو ولاية أو أثر عظيم من الدين على الجملة. • ل الا تتم الدعوة الدينية من غير عصبية. الأوطان الكثيرة القبائل و العصائب قل أن تستحكم فيها دولة. الظلم مؤذن بخراب العمران. الحضيارة غاية العمران و نهاية لعمره و هي مؤذنة بفساده. • الأمصار التي تكون كراسي للملك تخرب بخراب الدولة و انقراضها. السعادة و الكسب في الدنيا يحصلان غالبا لأهل الخضوع و التملق. القائمون بأمور الدين من القضياءو الفتيا و التدريس و الإمامة و الخطابة والأذان و نحو ذلك لا تعظم ثروتهم في الغالب.

$$
\begin{aligned}
& \text { • الصنائع لا بد لها من العلم. } \\
& \text { • رسوخ الصنائع في الأمصيار إنما هو برسوخ الحضيارة و طول أمدها. } \\
& \text { العرب أبعد الناس عن الصنائع. } \\
& \text { كثرة التآليف في العلوم عائقة عن التحصيل. } \\
& \text { الشدة على المتعلمين مضرة بهم. }
\end{aligned}
$$

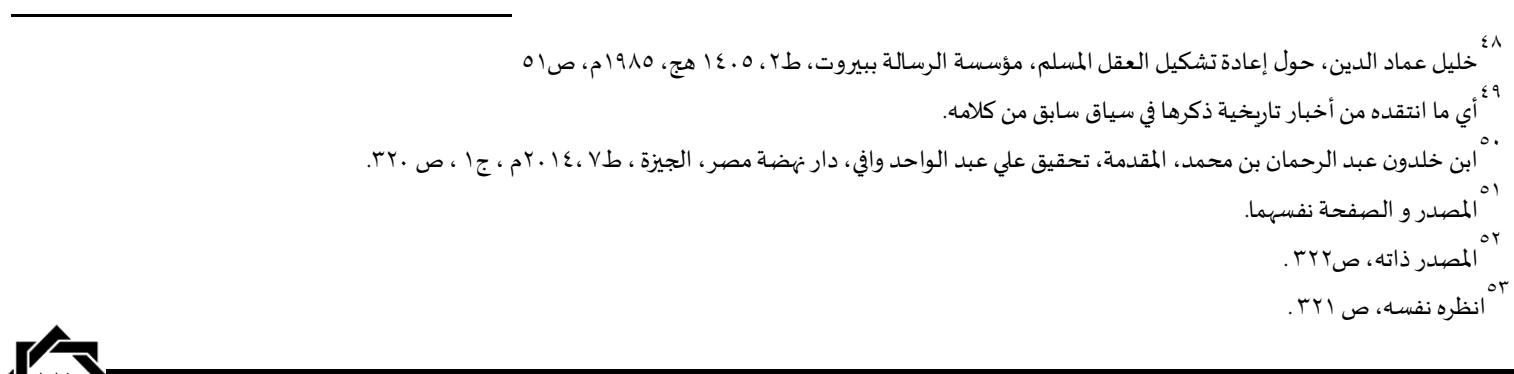






وأشـار ابن خلدون إلى أنه حاول اعتماد طريقة الإحصاء في منهجاه الاستقرائي ما أمكنه ذلك، ونبه المحققين بعده إلى أنها قد يفوته شيء في ذلك الإحصاء، فدورهم هو إصلاح ذلك وتقويمها (00) وفي هذا التنبيه دلالة على تواضعه العلمي و حرصهاء على أداء الأمانة العلمية. إعمال ابن الأزرق للقياس والاستقراء:

يتبين توظيف ابن الأزرق للقياس و الاستقراء من خلال تقسيماته و تفريعاته الكثيرة، فقد اعتمد طريقة المسالك، مثال ذلك ما فعلاه عند حديثه عن الركن السادس من أركان الملك اللازمة لقيامه : و هو : إقامة العدل، حيث تحدث عن عن مسلكين، قسمهما

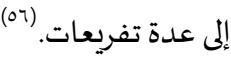
ومما يدل على ولوعاه بالقياس : إيراده قول عمر بن الخطاب رضي الله عنه: "... ثم اعرف الأشباه و الأمثال، فقس الأمور

عند ذلك بنظائرها" (ov) وقد قاس الحاضر على الماضي، و سهى ذلك اعتبارا، (م) و أورد عدة اعتبارات : فأثناء ذكره للعائق الثاني من العوائق الثمانية التي استقرأها و المنذرة بمنع دوام الملك قال: (اعتبار: قال ابن خلدون : و اعتبر ذلك في بني إسرائيل، لما دعاهم موسى عليه

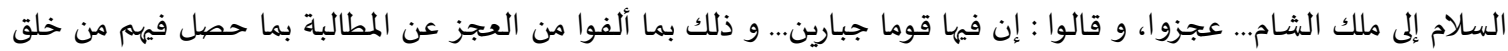

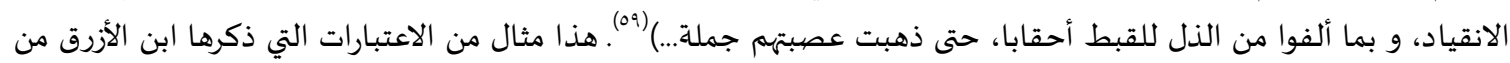

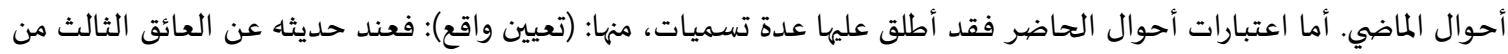
العوائق الثمانية المنذرة بمنع دوام الملك، ذكر اعتبارا، ثم قال:" تعيين واقع : ... كما وقع في الترك بالمشرق، فصيار غالب جندهم الموالي

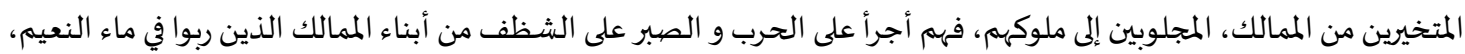
و نشأوا في الدعة و السكون) (7.). وقد جعل ابن الأزرق قياساته (أي اعتباراته الماضية و المعاصرة لزمانه) نتائج لاستقراءاته، ومنها: استقراؤه للعوائق المنذرة

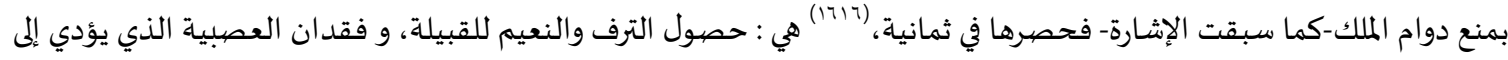

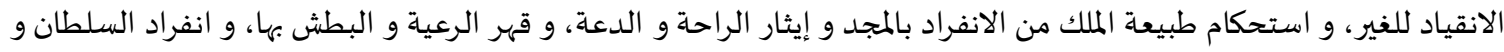

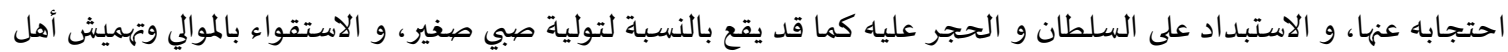
عصبيته، وانقسام الدولة الواحدة إلى دولتين.

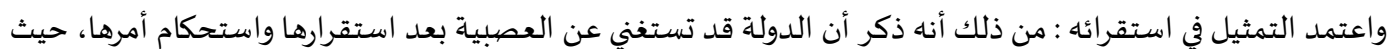

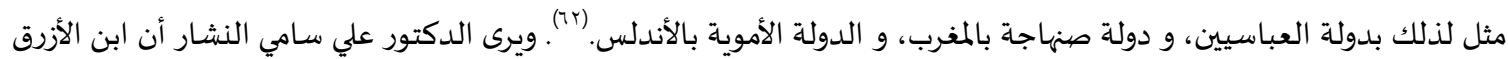



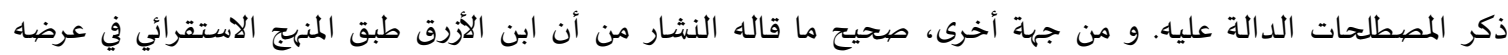

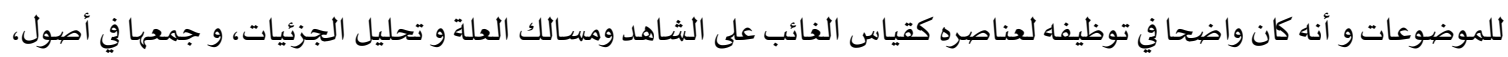
وإكثار التفريعات (7ع). ولا يخفى هنا أن ابن الأزرق جعل القياس أداة من أدوات الاستقراء. و لكناه متأثر إلى حد كبير بابن خلدون في منهجها، و قد

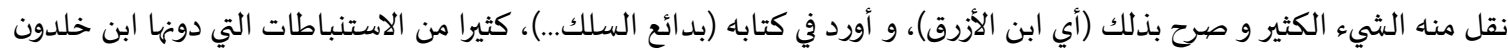
في كتابه 'العبر' و لاسيما المقدمة.



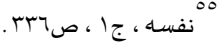

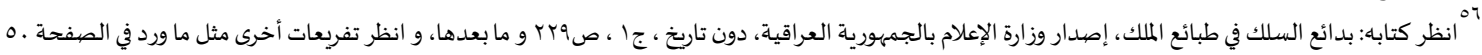

$$
\begin{aligned}
& \text { ror } \\
& \text { ^^ الاعتبار مصطلح قرآني، قال تعالى:" ... فاعتبروا يا أولي الأبصار"، سورة الحشر، الآية؟ }
\end{aligned}
$$



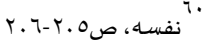

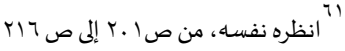

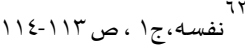

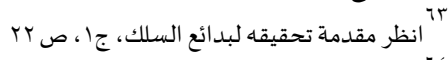

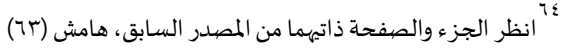




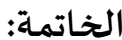

تتكامل علوم الوحي والعلوم الكونية والإنسانية، حيث تتقاطع وتلتقي أغلها في توظيف القياس والاستقراء. وبعد عرض

بعض تجليات و ملامح ذلك التكامل والتقاطع، يمكن الخلوص إلى الملاحظات الآتية :

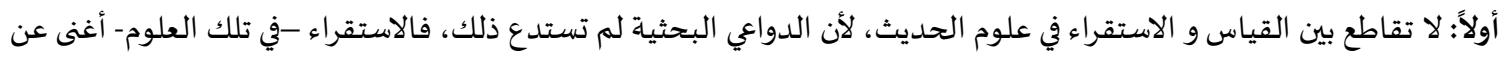
القياس.

ثانياً: في العلوم الشرعية والكونية و الإنسانية : يفيد الاستقراء التام القطع والحتمية بينما يفيد الاستقراء الناقص الظن و النسبية.

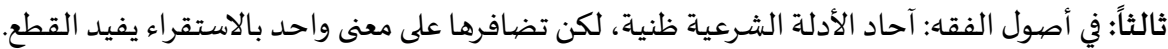

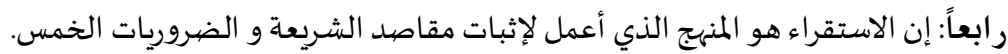

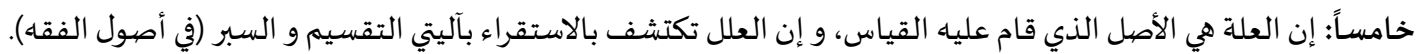



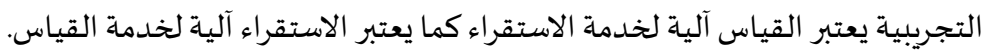

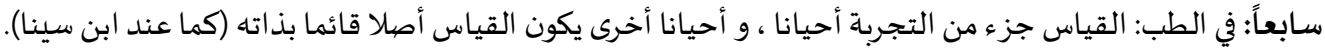


الاستقراء الحسي.

تاسعاً: في الفيزياء (البصريات): الهدف العام من الاستقراء هو الوصول إلى اليقين و الحقيقة (كما عند ابن الهيثم).

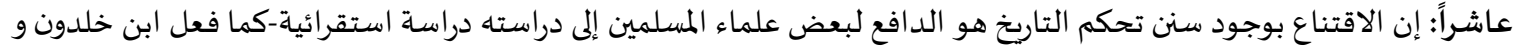

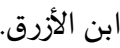

حادي عشر: لا مانع عند ابن خلدون من قياس الغائب على الشاهد في الوقائع التاريخية بشرط إدراك أوجاه الفرق.

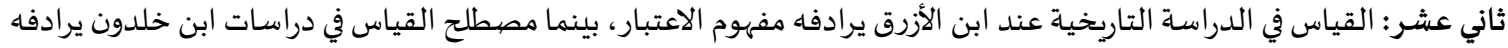

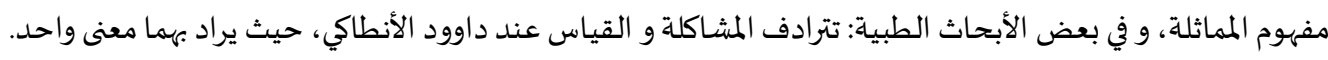

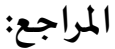

1. إبراهيم، مصطفى إبراهيم،(1999) منطق الاستقراء: المنطق الحديث ، إصدار ونشر دار المعارف بالإسكندرية.

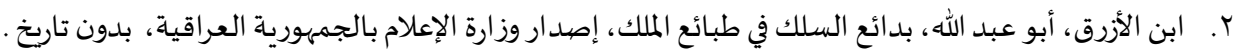

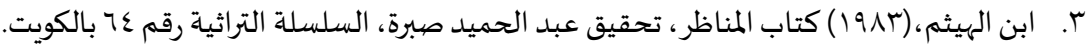

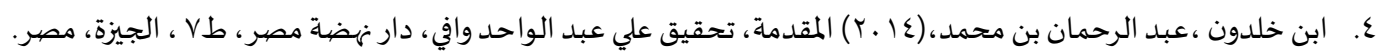
0 0. ابن رشد أبو الوليد، (9/V (1) رسائل ابن رشد الطبية، تحقيق جورج شحاته قنواتي وسعيد زيد ، تصدير إبراهيم مذكور، الهيئة المصرية

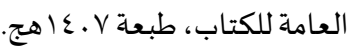
7. ابن سينا، أبو علي الحسين بن علي،(ع019) البرهان من كتاب الشفاء، تحقيق وتقديم عبد الرحمان بدوي، مكتبة الهضية المصرية بالقاهرة. V. ابن سينا، أبو علي الحسين بن علي، الشفاء (الطبيعيات)، مراجعة و تقديم إبراهيم مذكور ، تحقيق محمود قاسم، دار الكتاب العربي

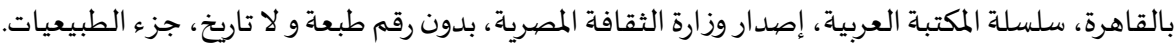

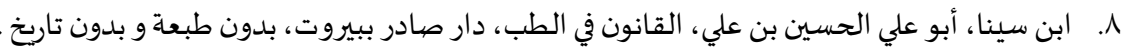

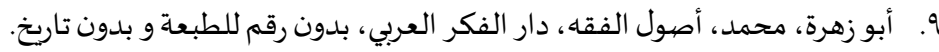

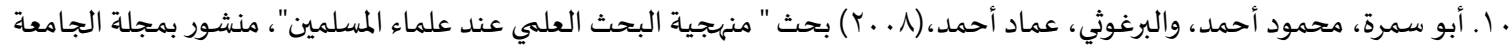

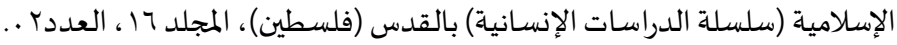

11. الأنطاكي، داوود بن عمر، تذكرة أولي الألباب الجامع للعجب العجاب، مكتبة الثقافة الدينية بالظاهر بمصر، بدون رقم طبعة ولا

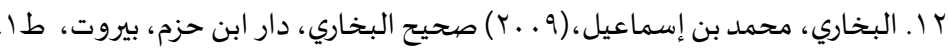

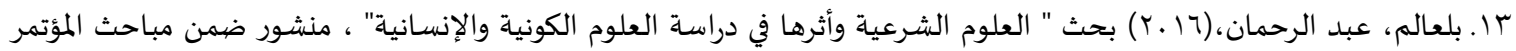

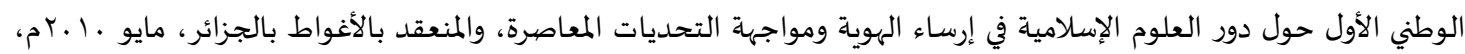
ونشر كتاب هذا المؤتمر من طرف دار المنظومة. 
عا . البندر، عبد الزهرة، (ץ991 ) "منهج الاستقراء في الفكر الإسلامي : أصوله وتطوره" ، إصدار ونشر دار الحكمة بلندن، طا ـ .

10. التهانوي، محمد علي، (1997) كشاف اصطيلاحات العلوم والفنون، تحقيق علي دحروج ، مكتبة لبنان ، طا ا.

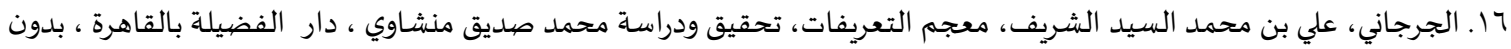
رقم طبعة ولا تاريخ.

VIV . جماعاة من كبار اللغويين العرب، (1991) "المعجم العربي الأساسي" ، إصدار المنظمة العربية للتربية والثقافة والعلوم ، طبعة بيروت .

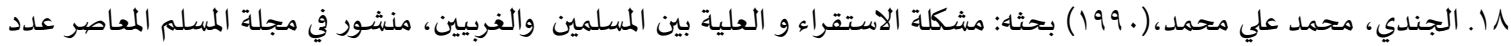

آ. الحسين، وليد بن علي،(ه . †) رسالة ماجستير بعنوان "القياس في القرآن والسنة النبوية : دراسة نظرية تطبيقية"، بجامعة الإمام

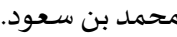

Y Y. الحسيني، محجوب محمد،(Y) (Y) بحث "جهود علماء المسلمين في إرساء المنهج العلمي"، منشور بمجلة دراسات تربوية التي تصددر عن

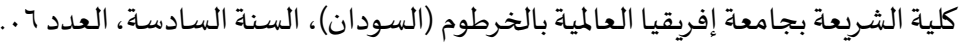

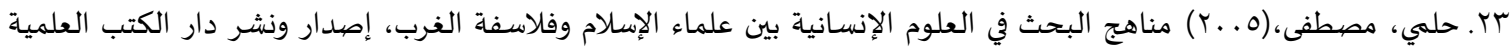

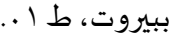
ع r. الخلف، عواد ، سعد، قاسم علي، (10 ـا الجامعون بين العلوم الشرعية والعلوم التجريبية ، سلسلة الثقافة الإسلامية، إصدار وحدة

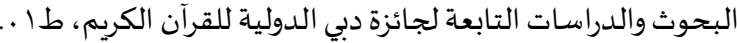

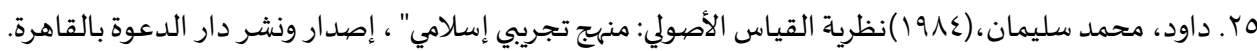

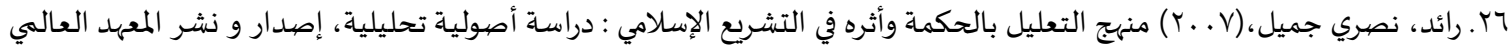

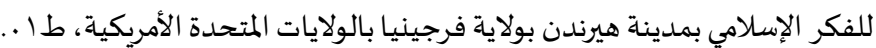

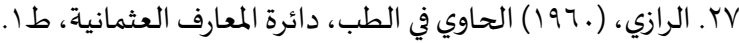

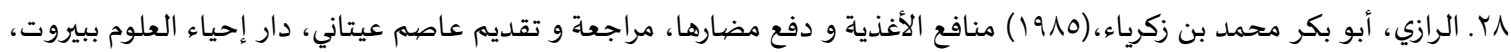

و r. زبدان، فهي، (19VV) الاستقراء والمنهج العلمي ، إصدار ونشر دار الجامعات المصرية بالإسكندرية.

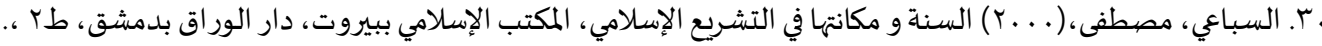

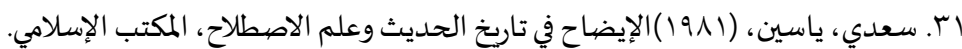

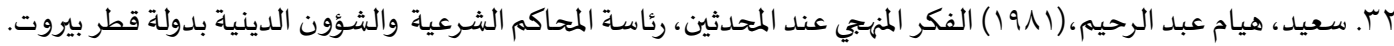

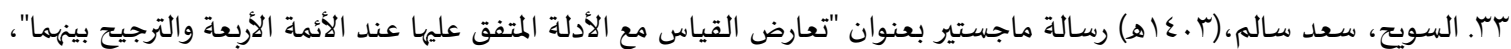
بجامعة الإمام محمد بن سعود. عَ. الشـاطبي، أبو إسحاق إبراهيم بن موسى، الموافقات في أصول الأحكام، تعليق الأستاذ محمد حسنين مخلوف، دار الفكر ببيروت، بدون رقم للطبعة وبدون تاريخ.

هr. شاهر ، محمد سعيد محمد، (9 . . †) رسالة دكتوراه بعنوان " أثر تحقيق المناط في الفتوى"، بالجامعة الأردنية. צr. الشيب، محمد صالح، (1991) رسالة دكتور اه بعنوان "تخصيص العلة ومخالفة القياس" ، بالجامعة الأردنية.



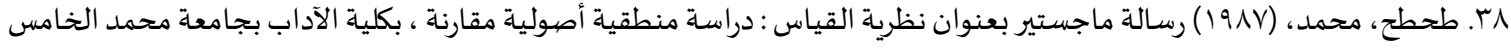
بالرباط (المغرب).

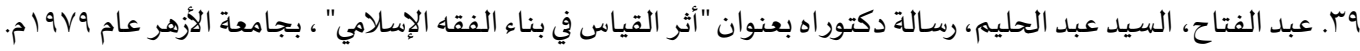

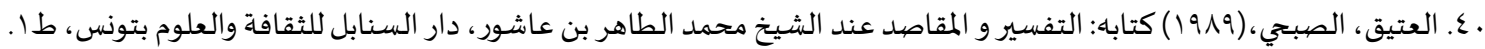

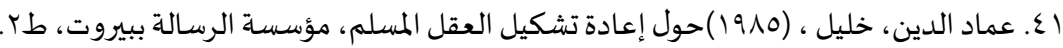

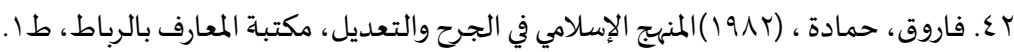

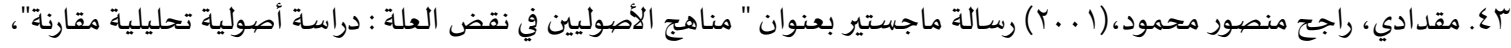
بالجامعة الأردنية. 




رفاد للدراسات والأبحاث

www.refaad.com

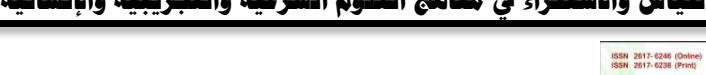

المجلة الدولية للدراسات الإسلامية المتخصصية

e-ISSN 2617-6246, p-ISSN 2617-6238

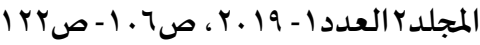

https://doi.org/DOI:10.31559/sis2019.2.1.5

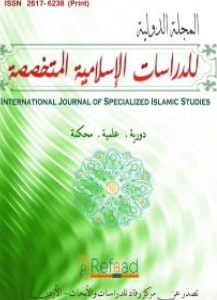

\title{
Intersections of Qiyas (Analogical Reasoning) and Induction in the Methods of Shari'a, Experimental, and Human Sciences
}

\author{
Mohamed El Filali \\ PhD- Faculty of Arts and Humanities- Mohammed V University- Morocco \\ mkbs114@gmail.com
}

\begin{abstract}
The sciences of revelation, cosmic science, and human sciences are integrated for Muslim scholars, one way of their complementarities: their intersection (ie, their interaction and involvement) in employing analogical reasoning and induction. It should be noted that the intersection between analogical reasoning and induction is absent in the science of Hadith, because the reasons for research did not call for that : there was no need to deploy induction as analogical reasoning was used. . The induction has been employed in the fundamentals of jurisprudence to prove the purposes of the Shari'a and the five essentials. The reason is the origin of the analogical reasoning. The reasons are discovered by induction using the mechanisms of division and mystery. And between the induction and analogical reasoning overlap and attraction: In the fundamentals of jurisprudence: induction is a methodical mechanism to serve analogical reasoning. In experimental science, induction and analogical reasoning serve each other. In medicine, the analogical reasoning was sometimes part of the experiment, and sometimes it was the origin. There is no doubt that the conviction of the existence of laws governingr history is the motivation of some Muslim scholars to study it inductively., such as what Ibn Khaldun and Ibn al-Azraq did.
\end{abstract}

Keywords: Qiyas (Analogical Reasoning), induction, intersection, integration, experimental sciences, forensic sciences, humanities.

\section{References:}

[1] 'bd Ạlftạh. Ạlsyd 'bd Ạlhllym, Rsạlẗ Dktwrạh B'nwạn "Ạtḥ̂ Ạlqyạs Fy Bnạ' Ạlfquh Ạlạslạmy" , Bjạm đ̈ Ạlạ̉zhr 'ạm (1979).

[2] 'mạd Ạldyn. Kḥlyl , Ḥwl Ạ 'ạdh Tshhkyl Ạl'ql Ạlmslm, Mw̉ssẗ Ạlrsạlh Bbyrwt, Ṭ2, (1985)

[3] Ạbn Ạlạ̉zrq. Ẩbw 'bd Allh, Bdạy` Ạlslk Fy Ṭbạy’ Ạlmlk, Ạsdạr Wzạrt̉ Ạlạ lạm Bạljmhwryh Ạl rạqyh, Bdwn Tạrykh.

[4] Ạbn Ạlhytḥm, Ktạb Ạlmnạzr, Tḥqyq ‘bd Ạlḥmyd Șbrh, Ạlslslh Ạltrạthַyh Rqm 64 Bạlkwyt, (1983)

[5] Ạbn Khlldwn .'bd Ạlrḥmạn Bn Mḥmd, Ạlmqdmh, Thquq 'la 'bd Ạlwạhd Wạfy, Dạr Nhḍ̆ Mṣr, Ṭ7, Aljyzh, Mṣr, (2014)

[6] Ạbn Rshạd Ạbw Ạlwlyd, Rsạyl Ạbn Rshhd Ạlṭbyh, Tḥyq Jwrj Shhạth Qnwạty Ws'yd Zyd, Tṣdyr Ạbrạhym Mdh̄kwr, Ạlhyỷh Ạlmșryh Ạl'ạmh Llktạb, Ṭb ‘̈̈ 1407hj, (1987)

[7] Ạbn Synạ. Ạ̉bw 'ly Ạlḷ̣syn Bn 'ly, Ạlbrhạn Mn Ktạb Ạlsḥfạ', Tḥqyq Wtqdym 'bd Ạlrḥmạn Bdwy, Mktbë Ạlnhụh Ạlmșryh Bạlqạhrh, (1954) 
[8] Ạbn Synạ. Ạ̉bw 'ly Ạlḥsyn Bn 'ly, Ạlqạnwn Fy Ạlṭb, Dạr Șạdr Bbyrwt, Bdwn Ṭb ‘̈ W Bdwn Tạrykh.

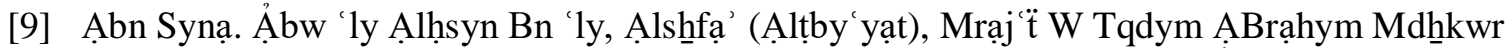
, Thqyq Mḥmwd Qạsm, Dạr Ạlktạb Ạl rby Bạlqạhrh, Slslï Ạlmktbh Al Al rbyh, Ạsdạr Wzạr

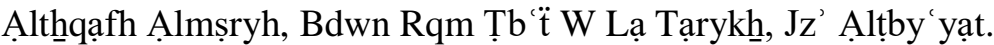

[10] Abrạhym. Mșța Ạbrạhym, Mnțq Ạlạstqrạ’: Ạlmnțq Ạlḥdythِ , Ạsdạr Wnsḥr Dạr Ạlm 'ạrf Bạlạskndryh, (1999)

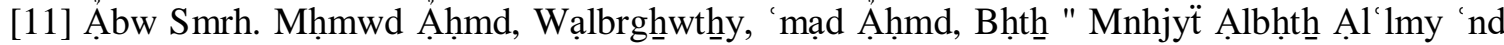
'Imạ’ Ạlmslmyn", Mnshowr Bmjlẗ Ạljạm'h Ạlạslạmyh (Slslï Ạldrạsạt ẠlậNsạnyh) Bạlqds (Flstyn), 16(2)(2008).

[12] Ạ̉bw Zhrh. Mḥmd, Ạṣwl Ạlfqh, Dạr Ạlfkr Ạl'rby, Bdwn Rqm Llțb ‘ h W Bdwn Tạrykh.

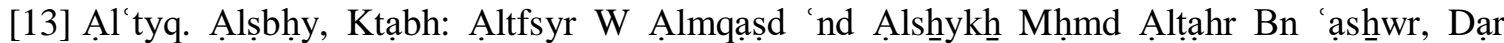
Ạlsnạbl Llth̆qạfh Wạl' lwm Btwns, Ṭ1, (1989)

[14] Alạ̉nțạky. Dạwwd Bn 'mr, Tdhkrh Ạ̉wla Ạlạ̉lbạb Ạljạm' Ll'jb Ạl'jạb, Mktbë Ạltḥqạfh Ạldynyh Bạlzạhr Bmșr, Bdwn Rqm Ṭb ‘̈ Wlạ Tạrykh̆.

[15] Ạlbkḥạry. Mḥmd Bn Ạsmạ yl, Șhỵḥ Ạlbkḥạry, Dạr Ạbn Ḥzm, Byrwt, Ṭ1, (2009)

[16] Ạlbndr. 'bd Ạlzhrh, "Mnhj Ạlạstqrạ’ Fy Ạlfkr ẠlạSlạmy : Ạ̉ṣwlh Wtṭwrh", Ạsdạr Wnsḥr Dạr Ạlḥkmh Blndn, Ṭ01, (1992).

[17] Ạlḥsyny. Mḥjwb Mḥmd, Bḥtḥ "Jhwd 'lmạ’ Almslmyn Fy Ạrsạ’ Ạlmnhj Ạl'lmy", Mnshwwr

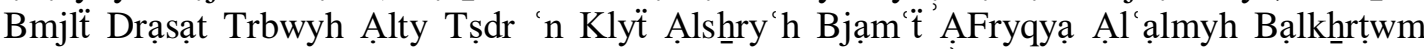
(Ạlswdạn), Ạlsnh Ạlsạdsh, Ạl'dd 06, (2017)

[18] Ạlḥsyn. Wlyd Bn 'ly, Rsạlẗ Mạjstyr B'nwạn "Ạlqyạs Fy Ạlqrận Wạlsnh Ạlnbwyh: Drạsh Nẓryh Tṭbyqyh", Bjạm ‘̈ Alạmạm Mḥmd Bn S'wd, (2005)

[19] Ạljndy. Mḥmd 'ly Mḥmd, Bḥtḥh: Mshnklë Ạlạstqrạ' W Ạl'lÿ̈ Byn Ạlmslmyn Wạlgḥrbyyn, Mnshwwr Fy Mjlï Ạlmslm Ạlm ’ạșr 'dd 57, (1990)

[20] Ạljrjạny. 'ly Bn Mḥmd Ạlsyd Ạlsḩryf, M’jm Ạlt'ryfạt, Tḥqyq Wdrạsä Mḥmd Ṣdyq Mnshạawy , Dạr Ạlfḍlh Bạlqạhrh, Bdwn Rqm Ṭb đ̈ Wlạ Tạrykh.

[21] Alkhllf. 'wạd , S'd, Qạsm 'ly, Aljạm wn Byn Ạl'lwm Ạlsḥr'yh Wạl'lwm Ạltjirybyh , Slslï Ạlthquafh Ạlạslạmyh, ẠṢdạr Wḥdt̉ Ạlbḥwth Wạldrạsạt Ạltạb 'h Ljậyzh Dby Ạldwlyh Llqrận Ạlkrym, Ṭ01, (2015)

[22] Alrạzy. Ảbw Bkr Mḥmd Bn Zkryạ’, Mnạf‘ Alạ̉ghndhhyh W Df 'Mḍarhạ, Mrạj'h W Tqdym 'ạșm 'ytạny, Dạr Ạhyạ’ Ạl 'lwm Bbyrwt, Ț3, (1985)

[23] Ạlrạzy, Ạlhạawy Fy Ạlțb, Dậỹü Ạlm‘ạrf Ạl tḥmạnyh, Ṭ1, (1960).

[24] Ạlsbạ̣y. Mștfy, Ạlsnh W Mkạnthạ Fy Ạltshِry` Ạlạslạmy, Ạlmktb Ạlạslạmy Bbyrwt, Dạr Ạlwrạq Bdmsh̆ $\underline{\text { q }}$, Ț2, (2000).

[25] Alshạtbyy. Ạ̉bw AShạq ABrạhym Bn Mwsa, Ạlmwạaqạt Fy Ạ̉ṣwl Ạlạ̉hkạm, T'lyq Ạlạ̉stạdh Mḥmd Ḥsnyn Mḳhlwf, Dạr Ạlfkr Bbyrwt, Bdwn Rqm Llțb`h Wbdwn Tạrykh.

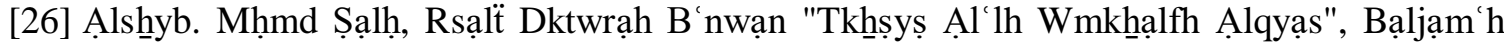
Alạ̉rdnyh, (1998)

المجلة الدولية للدراسات الإسلامية المتخصصية ـ المجلدج، العددا - 19 ب ب 
[27] Alswyḥ. S'd Sạlm, Rsạlẗ Mạjstyr B'nwạn "T'ạrḍ Alqyạs M' Ạlạ̉dlh Ạlmtfq 'lyhạ 'nd Ạlạ̉ỷmh Ạlạ̉rb ‘h Wạltrjyḥ Bynhmạ", Bjạm ‘̈ Ạlạmạm Mḥmd Bn S‘ wd, (1403h)

[28] Ạlthạnwy. Mḥmd 'ly, Kshạaf Ạșṭlạhạt Ạl lwm Wạlfnwn, Tḥqyq 'ly Dḥrwj, Mktbë Lbnạn, Ṭ1, (1996).

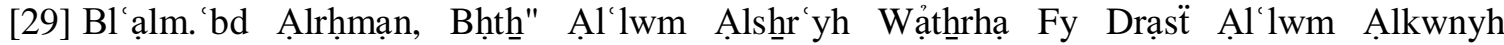

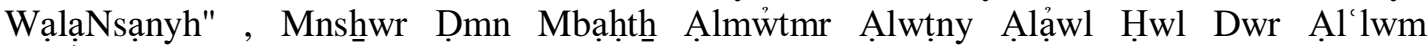
Alạslạmyh Fy ARsạ' Allhwyh Wmwạjhh Ạltḥdyạt Ạlm 'ạșrh, Wạlmn'qd Bạlạghhwạt Bạljzậ̉r, Mạyw 2010m, Wnsḥr Ktạb Hdhạ Ạlmw̉tmr Mn Ṭrf Dạr Ạlmnẓwmh, (2016)

[30] Dạwd. Mḥmd Slymạn, Nẓrÿ̈ Ạlqyạs Ạlạ̉ṣwly: Mnhj Tjryby Ạsslạmy, Ạssdạr Wnsḥr Dạr Ạld'wh Bạlqạhrh, (1984)

[31] Fạrwq. Ḥmạdh , Ạlmnhj Ạlạslạmy Fy Ạljrḥ Wạlt’ dyl, Mktbẗ Ạlm ậrf Bạlrbạt, Ṭ1, (1982)

[32] Ḥlmy. Mșṭa, Mnạhj Albḥ̣tḥ Fy Al'lwm Ạlạnsạnyh Byn 'Imạ’ Ạlạslạm Wflạsfh Ạlgh̆rb, Ạsdạr Wnsḥr Dạr Ạlktb Ạl'lmyh Bbyrwt, Ț 01, (2005).

[33] Ḥsb Ạllh. 'ly, Ạș̣wl Ạltsḥry' Ạlạ̦Slạmy, Dạr Ạlm ’ạrf Bmṣr, Ṭ5, (1976).

[34] Ḥsn. Ṣqr Nạdyh, Ạl'lm W Mnạhj Ạlbḥthِ Fy Ạlḥ̣ạrh Ạlạslạmyh, Mktb Ạlnhụh Ạlmṣryh Bạlqạhrh, (1991)

[35] Jmạ h Mn Kbạr Ạllgḥwyyn Ạl'rb, "Ạlm'jm Ạl'rby Ạlạ̉sạsy", Ạsdạr Ạlmnẓmh Ạl'rbyh Lltrbyh Wạlthquạfh Wạl'lwm, Țb đ̈ Byrwt, (1991).

[36] Mqdạdy. Rạjḥ Mnṣwr Mḥmwd, Rsạlt Mạjstyr B'nwạn" Mnạhj Ạlạ̉ṣwlyyn Fy Nqụ Ạl'lh: Drạsh Ạ̣șlyh Tḥlylyh Mqạrnh", Bạljạm'h Ạlạ̉rdnyh, (2001)

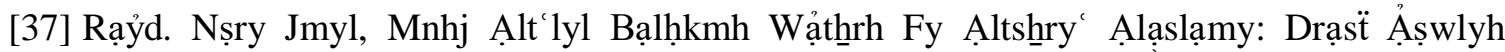
Tḥlylyh, Ạsdạr W Nsḥr Ạlm hd Ạl'ạlmy Llfkr Ạlạslạmy Bmdynẗ Hyrndn Bwlạyë Frjynyạ Bạlwlạyạt Ạlmthọh Ạlạ̉mrykyh, Ṭ01, (2007)

[38] S'yd. Hyạm 'bd Ạlrḥym, Ạlfkr Ạlmnhjy 'nd Ạlmḥdthnyn, Rỷạsẗ Ạlmḥạkm Ạlsḥr'yh Wạlsȟ̉wn Ạldynyh Bdwlẗ Qțr Byrwt, (1981)

[39] Shạhr. Mḥmd S'yd Mḥmd, Rsạlẗ Dktwrạh B'nwạn" Ạ̉tḥr Tḥqyq Ạlmnạt Fy Ạlftwy", Bạljạm h h Ạlạ̉rdnyh, (2009)

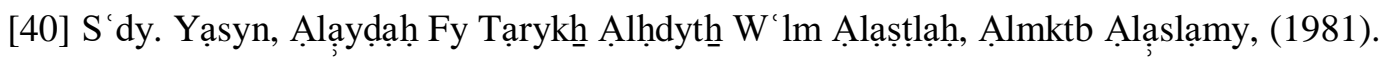

[41] Șạlḥ. N’mạn, Rsạlẗ Mạjstyr B’nwạn " Ạlqyạs Byn Ạlmnțq Wạ̉ṣwl Ạlfqh ", Bjạm ṭ Ạlạ̉myr 'bd Ạlqạdr Bạljzạyr, (1993)

[42] Țhṭḥ. Mḥmd, Rsạlẗ Mạjstyr B'nwạn Nzryä Ạlqyạs: Drạsẗ Mnțqyh Ạ̉ṣwlyh Mqạrnh, Bklÿ̈ Ạlậdạb Bjạm‘̋̈ Mḥmd Ạlkhạms Bạlrbạt (Ạlmghnrb), (1987).

[43] Zydạn. Fhmy, Ạlạstqrạ' Wạlmnhj Ạl'lmy, Ạsdạr Wnsḥr Dạr Ạljạm'ạt Ạlmṣryh BạlạSkndryh, (1977). 